\title{
Degradation of Bile Acids by Soil and Water Bacteria
}

\author{
Franziska Maria Feller ${ }^{1,+}$, Johannes Holert ${ }^{1,+}$, , Onur Yücel ${ }^{1}$ and Bodo Philipp ${ }^{1,2, *}$ \\ 1 Institute for Molecular Microbiology and Biotechnology, University of Münster, Corrensstr. 3, \\ 48149 Münster, Germany; franziska.feller@uni-muenster.de (F.M.F.); johannes.holert@uni-muenster.de (J.H.); \\ onuryuecel@googlemail.com (O.Y.) \\ 2 Fraunhofer Institute for Molecular Biology and Applied Ecology IME, Auf dem Aberg 1, \\ 57392 Schmallenberg, Germany \\ * Correspondence: bodo.philipp@uni-muenster.de; Tel.: +49-251-833-9827; Fax: +49-251-833-8388 \\ + Contributed equally.
}

Citation: Feller, F.M.; Holert, J.;

Yücel, O.; Philipp, B. Degradation of Bile Acids by Soil and Water Bacteria. Microorganisms 2021, 9, 1759.

https://doi.org/10.3390/

microorganisms 9081759

Academic Editor: Jason Ridlon

Received: 30 June 2021

Accepted: 12 August 2021

Published: 17 August 2021

Publisher's Note: MDPI stays neutral with regard to jurisdictional claims in published maps and institutional affiliations.

Copyright: (C) 2021 by the authors. Licensee MDPI, Basel, Switzerland. This article is an open access article distributed under the terms and conditions of the Creative Commons Attribution (CC BY) license (https:// creativecommons.org/licenses/by/ $4.0 /)$.

\begin{abstract}
Bile acids are surface-active steroid compounds with a $\mathrm{C}_{5}$ carboxylic side chain at the steroid nucleus. They are produced by vertebrates, mainly functioning as emulsifiers for lipophilic nutrients, as signaling compounds, and as an antimicrobial barrier in the duodenum. Upon excretion into soil and water, bile acids serve as carbon- and energy-rich growth substrates for diverse heterotrophic bacteria. Metabolic pathways for the degradation of bile acids are predominantly studied in individual strains of the genera Pseudomonas, Comamonas, Sphingobium, Azoarcus, and Rhodococcus. Bile acid degradation is initiated by oxidative reactions of the steroid skeleton at ring A and degradation of the carboxylic side chain before the steroid nucleus is broken down into central metabolic intermediates for biomass and energy production. This review summarizes the current biochemical and genetic knowledge on aerobic and anaerobic degradation of bile acids by soil and water bacteria. In addition, ecological and applied aspects are addressed, including resistance mechanisms against the toxic effects of bile acids.
\end{abstract}

Keywords: steroid degradation; bile acids; bacterial metabolism; cholic; deoxycholic; chenodeoxycholic

\section{Bile Acids and Their Occurrence in the Environment}

Bile acids, or bile salts in their de-protonated state, are surface-active steroid compounds that serve many functions in the digestive tract of vertebrates [1,2] and as regulatory signaling compounds [3]. These functions and the interplay of bile acids with gastrointestinal bacteria [4-10] are described in the accompanying review articles of this special issue. The focus of this review is on the current knowledge about the metabolic pathways of soil and water bacteria, which use bile acids as a carbon and energy source under aerobic and anaerobic conditions and their ecological and biotechnological implications.

More than $90 \%$ of vertebrae bile acids are typically re-adsorbed from the intestine during the enterohepatic cycle. The rest is released into the environment by feces and urine. For example, humans release 400-600 mg of bile acids per person and day [4], adding up to about $180 \mathrm{~g}$ per year. A large input of bile acids into the environment originates from farm animals. $1 \mathrm{~g}$ of cow feces contains about $1 \mathrm{mg}$ cholic acid and $3 \mathrm{mg}$ deoxycholic acid, and $1 \mathrm{~g}$ chicken feces can contain up to $7.5 \mathrm{mg}$ chenodeoxycholic acid [11]. Theoretically, this could lead to bile acid concentrations in the millimolar range of up to $20 \mathrm{mM}$ when animal excretions are used on agricultural land as fertilizer [12]. In accordance with that, about $0.3 \mathrm{mM}$ deoxycholic and about $0.5 \mathrm{mM}$ chenodeoxycholic acid were detected in cow and poultry manure-runoff simulations [13], and even in rivers up to $13 \mathrm{nM}$ of lithocholic acid and up to $76 \mathrm{nM}$ of deoxycholic acid were detectable [14]. Bile acids are also released by aquatic vertebrates, functioning as signaling compounds [15,16].

As a result of their widespread release by vertebrates, bile acids constitute a rich nutrient source for many bacteria in soils and water, in particular near fecal pellets of 
vertebrates and in manure-fertilized areas (Figure 1). In accordance with this, rapid chenodeoxycholic acid degradation was observed in soil slurries from agricultural fields that were spiked with this bile acid [12]. Bacterial growth in enrichment cultures containing bile acids as substrates inoculated with soil or freshwater usually occurs within $24-48 \mathrm{~h}$ and bile acid-degrading bacteria can readily be isolated from terrestrial and limnic habitats [17-19]. Further supporting this, a recent study analyzing steroid degradation genes in metagenomes from diverse environments revealed that soils and rhizosphere, as well as marine and selected freshwater environments, are prominent habitats for steroid-degrading bacteria [20]. As bile acids are highly reduced and carbon-rich compounds, they provide an attractive carbon- and energy source, particularly in nutrient-poor soils and waters. Pseudomonas stutzeri Chol1 has a molar growth yield of about $250 \mathrm{~g}$ dry mass per mol cholic acid under aerobic conditions [19]. This suggests that about 25 mol adenosine triphosphate (ATP) can be derived from the degradation of $1 \mathrm{~mol}$ cholic acid, considering that $1 \mathrm{~mol}$ of ATP is required for the formation of $10 \mathrm{~g}$ of dry mass [21].

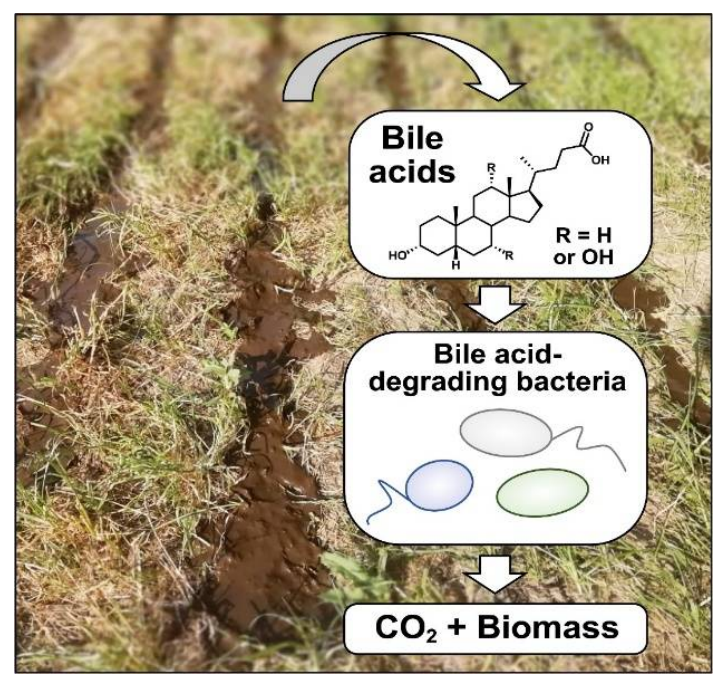

Figure 1. Manure fertilizer on agricultural fields as a source for bile salts, which can be used as a carbon and energy source by heterotrophic bacteria.

In spite of their good degradability, bile acids can be used as paleontological markers [22] in some environments where their degradation is hindered by adverse environmental factors such as unfavorable $\mathrm{pH}$, temperature, or salinity, desiccation, or a lack of suitable electron acceptors.

\section{Bacterial Bile Acid Degradation}

\subsection{Diversity of Bile Acid-Degrading Bacteria}

In recent years, many bile acid-degrading bacteria have been isolated from different environments such as meadows, freshwater, and marine habitats. All these strains belong to the Proteobacteria or Actinobacteria. Among the Proteobacteria, individual strains of the genera Sphingomonas, Sphingobium, Novosphingobium ( $\alpha$-Proteobacteria; $([18,23])), C^{-}$ mamonas, Azoarcus, Zoogloea ( $\beta$-Proteobacteria; $[18,24,25])$, Pseudomonas, Pseudoalteromonas and Shewanella ( $\gamma$-Proteobacteria; $[17,19,26,27])$ have been identified to be able to degrade bile acids. Among the Actinobacteria, several members of the genus Rhodococcus [28,29], as well as individual strains from the genera Thermomonospora, Amycolatopsis [27], Dietzia [18], Gordonia [17], and Nocardia [30] are able to grow with and metabolize bile acids.

The apparent restriction of bile acid degradation to the Actinobacteria and $\alpha-, \beta-$, and $\gamma$-Proteobacteria is strongly supported by two recent studies analyzing the occurrence of steroid degradation genes in sequenced genomes and metagenomes [20,27], which found aerobic steroid degradation genes only in members of these taxa. Homologs of known bile acid degradation proteins were only found in genomes of the Actinobacteria genera Rhodococcus, Gordonia, and Saccharomonospora and in genomes of the Proteobacteria genera 
Comamonas, Glaciecola, Marinobacterium, Pseudoalteromonas, Pseudomonas, Shewanella, and Sphingomonas [27].

\subsection{General Aspects of Metabolic Bile Acid Degradation Pathways}

Bacterial bile acid degradation has primarily been studied with cholic acid (compound I) as a model substrate [31] and to a lesser extent with the differently hydroxylated bile acids chenodeoxycholic (II) and deoxycholic acid (III, Figure 2A). Degradation of lithocholic acid (IV) represents a special scenario since its A-ring oxidized derivatives are also natural intermediates of the bacterial cholesterol and phytosterol degradation pathway [32]. Transcriptomic studies in a bile acid and sterol degrading Actinobacterium suggested that lithocholic acid is degraded by a mix of cholesterol and bile acid degradation-specific reactions [30].

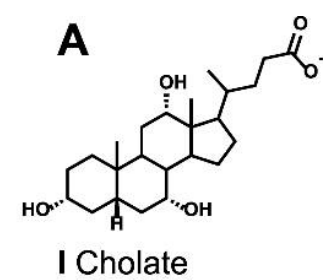

I Cholate

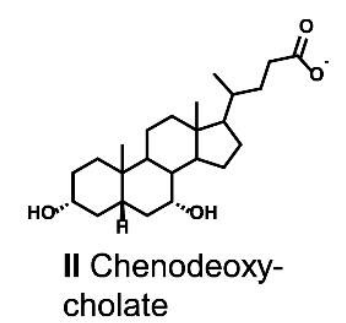

cholate

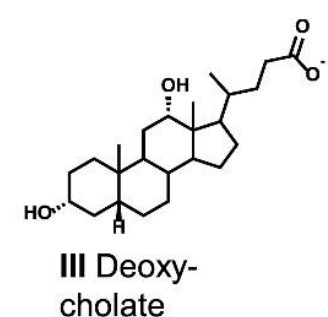

cholate
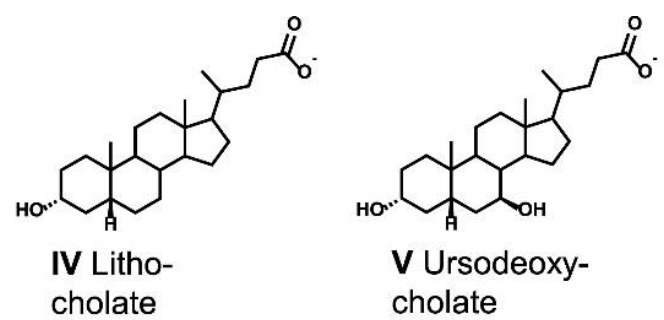

cholate

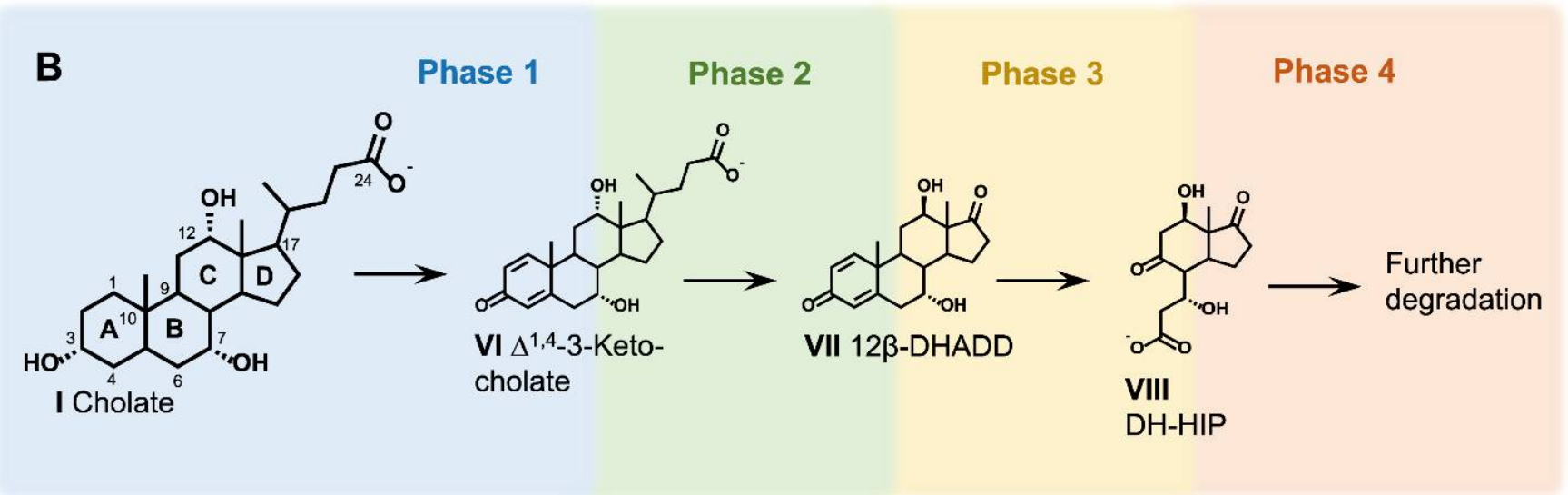

Figure 2. General aspects of bile acid degradation. (A) Structures of the most common bile acids in humans. (B) General scheme of bile acid degradation by bacteria. For bile acids, the respective deprotonated bile salts are depicted. Abbreviations: $12 \beta$-DHADD, $7 \alpha, 12 \beta$-Dihydroxy-androsta-1,4-diene-3,17-dione; DH-DHIP, 3',7-Dihydroxy-H-methyl-hexahydro-indanone-propanoate.

Aerobic degradation of cholic acid and other bile acids has predominantly been studied in Pseudomonas stutzeri Chol1 [31,33,34], Pseudomonas putida DOC21 [17,35], Comamonas testosteroni [24,36-39], Sphingobium sp. strain Chol11 [18,23,40-42], and Rhodococcus jostii RHA1 $[28,43]$. Complete anaerobic degradation of bile acids has been studied in the facultative anaerobic, denitrifying $\beta$-proteobacterium Azoarcus sp. strain Aa7 (Yücel et al., 2017). Genetic, biochemical, and physiological studies have shown that many bile acid degradation reactions, especially for the degradation of the steroid nucleus, are homologous to the respective reaction steps known from bacterial cholesterol or testosterone degradation pathways [24,32,44,45].

Bile acid degradation can be divided into four phases (Figure 2B): (1) partial oxidation of the A-ring (Figure 3), (2) stepwise removal of the $\mathrm{C}_{5}$ carboxylic side chain, including the release of an acetyl-CoA and a propionyl-CoA residue (Figure 4), (3) successive opening of the B- and A-ring and degradation of the former A-ring (Figure 5), and (4) degradation of the remaining C/D-rings (Figure 6). While this unifying scheme appears to occur in most bile acid-degrading bacteria, some individual degradation pathways exhibit specific differences in the order of the reaction sequences [43] and in individual biochemical reactions [40]. 
The A-ring oxidation, side chain, and C/D-ring degradation phases do not require elemental oxygen as co-substrate and are largely homologous in the anaerobic and aerobic degradation pathways. However, cleavage of the B- and A-ring (phase 3) differs significantly between aerobic and anaerobic conditions: elemental oxygen is used by oxygenases to open the steroid ring system under aerobic conditions $[46,47]$, while molybdoenzymes catalyze a water-based ring-opening under anaerobic conditions. The respective aerobic and anaerobic degradation pathways of the steroid nucleus are known as the 9,10-seco pathway [48] and the 2,3-seco pathway [25,49,50], respectively. The facultatively denitrifying Azoarcus sp. strain Aa7 is the first reported bile acid-degrading bacterium that uses either the 9,10-seco or the 2,3-seco pathway, depending on the availability of oxygen [25].

In general, bile acid degradation genes are organized in large gene clusters [24,27,28,32,51], which often contain sub-clusters for individual reaction steps such as side chain and ring degradation (Table 1). The genomes of many bile acid-degrading Proteobacteria have a single gene cluster for bile acid degradation as found in P. stutzeri Chol1 [51] and C. testosteroni TA441 [39,52]. Others have multiple distinct gene clusters, such as Pseudoalteromonas haloplanktis [27] or Azoarcus sp. strain Aa7 (Yücel et al., 2017). In Sphingobium sp. strain Chol11, three clusters and several single genes have been identified to be involved in bile acid metabolism $[23,41]$. The genome of $R$. jostii RHA1 comprises two distinct gene clusters for cholic acid and cholesterol degradation, which are differentially expressed depending on the steroid carbon source [28]. However, genes involved in the C/D-ring degradation of cholic acid and cholesterol are only found in the cholesterol degradation cluster.

Genes and proteins characterized and predicted to be involved in bile acid degradation in P. stutzeri Chol1, C. testosteroni CNB-2, Sphingobium sp. strain Chol11, and R. jostii RHA1 are summarized in Table 1.

Table 1. Characterized and predicted bile acid degradation genes (locus tags) located in the steroid degradation gene clusters of Pseudomonas stutzeri Chol1, Comamonas testosteroni CNB-2, Rhodococcus jostii RHA1, and Sphingobium sp. strain Chol11. Protein names are given in parentheses when available and are taken from the corresponding literature. Characterized genes and proteins are bold.

\begin{tabular}{|c|c|c|c|c|c|}
\hline $\begin{array}{c}\text { Bile Acid Degradation } \\
\text { Pathway }\end{array}$ & Function & P. stutzeri Chol1 & C. testosteroni CNB-2 $* * *$ & R. jostii RHA1 & $\begin{array}{l}\text { Sphingobium sp. } \\
\text { Strain Chol11 }\end{array}$ \\
\hline $\begin{array}{c}\text { Cleavage of conjugated } \\
\text { bile acids }\end{array}$ & Bile salt amidase & C211_RS11020 & $\begin{array}{l}\text { CTCNB1_RS06560 (ORF26) } \\
\text { CTCNB1_TS06555 (ORF25) }\end{array}$ & $\begin{array}{c}\text { unknown } \\
\text { (RHA1_RS22310) }\end{array}$ & Nov2c227 (Bsa) \\
\hline \multirow{8}{*}{$\begin{array}{l}\text { C5 side-chain } \\
\text { degradation }\end{array}$} & CoA-ligase & C211_RS11125 (StdA1 *) & CTCNB1_RS06840 & RHA1_RS28415 (CasG) & Nov2c230 (SclA) \\
\hline & ACADs & C211_RS11115 (Scd1A) & CTCNB1_RS06830 & RHA1_RS28395 (CasC) & Nov2c221 (Scd4A) \\
\hline & & C211_RS11120 (Scd1B) & CTCNB1_RS06835 & - & Nov2c222 (Scd4B) \\
\hline & Enoyl-CoA hydratase & C211_RS11210 (Shy1) & CTCNB1_RS06880 & RHA1_RS28400 (CasD) & absent \\
\hline & Steroid aldolase & C211_RS11205 (Sal1) & CTCNB1_RS06875 & absent & absent \\
\hline & $\begin{array}{l}\text { Steroid aldehyde } \\
\text { dehydrogenase }\end{array}$ & C211_RS11010 (Sad) & CTCNB1_RS06680 & absent & absent \\
\hline & $\begin{array}{l}\text { 2-hydroxy-CoA } \\
\text { dehydrogenase }\end{array}$ & absent & absent & RHA1_RS28410 & absent \\
\hline & Steroid thiolase & absent & absent & RHA1_RS28390 (CasB) & absent \\
\hline \multirow{6}{*}{$\begin{array}{l}\text { C3 side-chain } \\
\text { degradation }\end{array}$} & CoA-ligase & C211_RS11185 (StdA2 *) & CTCNB1_RS06820 & RHA1_RS28425 (CasI) & absent \\
\hline & ACADs & C211_RS11105 (Scd2A) & CTCNB1_RS06815 & RHA1_RS28440 (CasL) & absent \\
\hline & & C211_RS11090 (Scd2B) & CTCNB1_RS06800 & RHA1_RS28450 (CasN) & absent \\
\hline & Enoyl-CoA hydratase & C211_RS11085 (Shy2) & CTCNB1_RS06795 & RHA1_RS28445 (CasM) & absent \\
\hline & & C211_RS11095 & CTCNB1_RS06805 & RHA1_RS28455 (CasO) & absent \\
\hline & Steroid aldolase & C211_RS11100 (Sal2) & CTCNB1_RS06810 & RHA1_RS28460 (CasP) & absent \\
\hline
\end{tabular}


Table 1. Cont.

\begin{tabular}{|c|c|c|c|c|c|}
\hline $\begin{array}{c}\text { Bile Acid Degradation } \\
\text { Pathway }\end{array}$ & Function & P. stutzeri Chol1 & C. testosteroni $\mathrm{CNB}-2 * * *$ & R. jostii RHA1 & $\begin{array}{l}\text { Sphingobium sp. } \\
\text { Strain Chol11 }\end{array}$ \\
\hline \multirow{5}{*}{ A-ring oxidation } & $\begin{array}{l}3 \alpha \text {-Hydroxysteroid } \\
\text { dehydrogenase }\end{array}$ & C211_RS10975 & CTCNB1_RS06750 ( $3 \alpha-\mathrm{HSD})$ & unknown & Nov2c6 \\
\hline & $\begin{array}{l}\Delta^{1} \text {-Ketosteroid } \\
\text { dehydrogenase }\end{array}$ & $\begin{array}{c}\text { C211_RS11030 } \\
\left(\Delta^{1}-\text { KstD }\right)\end{array}$ & CTCNB1_RS06925 (TesH) & RHA1_RS28305 (KstD3) & Nov2c82 \\
\hline & & - & - & $\begin{array}{c}\text { RHA1_RS28380 } \\
\text { (KstD3b) }\end{array}$ & - \\
\hline & $\begin{array}{c}\Delta^{4}-5 \alpha \text {-Ketosteroid } \\
\text { dehydrogenase }\end{array}$ & C211_RS11110 & CTCNB1_RS06930 (TesI) & RHA1_RS27810 & Nov2c17 \\
\hline & $\begin{array}{c}\Delta^{4}-5 \beta \text {-Ketosteroid } \\
\text { dehydrogenase }\end{array}$ & Unknown & CTCNB1_RS06740 & RHA1_RS28420 (CasH) & $\begin{array}{c}\text { Nov2c19 } \\
\left(\Delta^{4}-5 \beta-K S T D 1\right)\end{array}$ \\
\hline \multirow{8}{*}{ 9,10-seco pathway } & $\begin{array}{c}\text { 3-Ketosteroid-9 } \alpha \\
\text { hydroxylase, oxygenase }\end{array}$ & C211_RS11300 & CTCNB1_RS06665 & $\begin{array}{c}\text { RHA1_RS28370 } \\
\text { (KshA3) }\end{array}$ & Nov2c407 \\
\hline & & - & - & - & Nov2c430 \\
\hline & & - & - & - & Nov2c440 \\
\hline & $\begin{array}{c}\text { 3-Ketosteroid-9 } \alpha \\
\text { hydroxylase, reductase }\end{array}$ & C211_RS11040 & CTCNB1_RS06935 (ORF17) & RHA1_RS28480 (KshB3) & absent \\
\hline & $\begin{array}{c}\text { 9,10-seco-steroid } \\
\text { hydroxylase, oxygenase }\end{array}$ & C211_RS11025 & CTCNB1_RS06920 (TesA2) & $\begin{array}{c}\text { RHA1_RS28325 } \\
\text { (HsaA3) }\end{array}$ & Nov2c349 \\
\hline & $\begin{array}{c}\text { 9,10-seco-steroid } \\
\text { hydroxylase, reductase }\end{array}$ & C211_RS11005 & CTCNB1_RS06915 (TesA1) & RHA1_RS28295 (HsaB3) & $\begin{array}{c}\text { absent } \\
\text { (Nov2c347) }\end{array}$ \\
\hline & $\begin{array}{l}9,10 \text {-seco-steroid } \\
\text { dioxygenase }\end{array}$ & C211_RS11215 & CTCNB1_RS06510 (TesB) & $\begin{array}{c}\text { RHA1_RS28330 } \\
\text { (HsaC3) }\end{array}$ & Nov2c350 \\
\hline & $\begin{array}{l}4,5,9,10 \text {-diseco-steroid } \\
\text { hydroxylase }\end{array}$ & C211_RS11155 & CTCNB1_RS06910 (TesD) & $\begin{array}{l}\text { RHA1_RS28300 } \\
\text { (HsaD3) }\end{array}$ & Nov2c348 \\
\hline \multirow{7}{*}{$\begin{array}{c}\text { C/D-ring (HIP) } \\
\text { side-chain degradation }\end{array}$} & CoA-ligase & C211_RS11045 (StdA3 *) & CTCNB1_RS06940 (ScdA) & $\begin{array}{c}\text { RHA1_RS22410 ** } \\
\text { (FadD3) }\end{array}$ & Nov2c359 \\
\hline & ACAD & C211_RS11065 (Scd3A) & CTCNB1_RS06570 (ScdC1) & RHA1_RS22390 ** & Nov2c367 \\
\hline & & C211_RS11070 (Scd3B) & CTCNB1_RS06575 (ScdC2) & RHA1_RS22415** & Nov2c361 \\
\hline & Enoyl-CoA hydratase & C211_RS11075 & CTCNB1_RS06585 (ScdD) & unknown & Nov2c364 \\
\hline & & C211_RS11270 & - & - & - \\
\hline & $\begin{array}{l}\text { 2-hydroxy-acyl-CoA } \\
\text { dehydrogenase }\end{array}$ & C211_RS11260 & CTCNB1_RS06565 (ScdE) & RHA1_RS22710** & $\begin{array}{c}\text { Absent } \\
\text { (Nov2c360, } \\
\text { Nov2c362) }\end{array}$ \\
\hline & HIP thiolase & C211_RS11275 & CTCNB1_RS06590 (ORF33) & RHA1_RS28520 & Nov2c358 \\
\hline \multirow{9}{*}{$\begin{array}{l}\text { C/D-ring (HIC) } \\
\text { degradation }\end{array}$} & $\begin{array}{l}\text { 5-OH HIC-CoA } \\
\text { reductase }\end{array}$ & C211_RS11235 & CTCNB1_RS06530 (ScdK) & $\begin{array}{c}\text { RHA1_RS22685 ** } \\
\text { (IpdC) }\end{array}$ & Nov2c354 \\
\hline & 5-Oxo HIC-CoA oxidase & C211_RS11265 & CTCNB1_RS06580 (ScdG) & $\begin{array}{c}\text { RHA1_RS22420 ** } \\
\text { (IpdF) }\end{array}$ & Nov2c363 \\
\hline & HIEC-CoA hydrolase & unknown & CTCNB1_RS06535 (ScdY) & $\begin{array}{l}\text { RHA1_RS27700 ** } \\
\text { (EchA20) }\end{array}$ & Nov2c355 \\
\hline & $\begin{array}{c}\text { COCHEA-CoA } \\
\text { hydrolase, } \alpha \text {-subunit }\end{array}$ & C211_RS11220 & CTCNB1_RS06515 (ScdL1) & $\begin{array}{c}\text { RHA1_RS22695 ** } \\
\text { (IpdA) }\end{array}$ & Nov2c351 \\
\hline & $\begin{array}{c}\text { COCHEA-CoA } \\
\text { hydrolase, } \beta \text {-subunit }\end{array}$ & C211_RS11225 & CTCNB1_RS06520 (ScdL2) & $\underset{\text { (IpdB) }}{\text { RHA1_RS22690 }}$ & Nov2c352 \\
\hline & $\beta$-Keto CoA thiolase & C211_RS11255 & CTCNB1_RS06550 (ScdF) & $\begin{array}{l}\text { RHA1_RS22430 ** } \\
\text { (FadA6) }\end{array}$ & Nov2c366 \\
\hline & ACAD & C211_RS11245 & CTCNB1_RS06540 (ORF21) & $\begin{array}{l}\text { RHA1_RS22400 ** } \\
\text { (FadE31) }\end{array}$ & Nov2c356 \\
\hline & ACAD & C211_RS11250 & CTCNB1_RS06545 (ORF22) & $\begin{array}{l}\text { RHA1_RS22395 ** } \\
\text { (FadE32) }\end{array}$ & Nov2c357 \\
\hline & Hydratase & C211_RS11230 & CTCNB1_RS06525 (ScdN) & RHA1_RS22405 & Nov2c353 \\
\hline \multirow{3}{*}{$\begin{array}{c}\text { 2-hydroxy-hexa-2,4- } \\
\text { dienoate } \\
\text { degradation }\end{array}$} & $\begin{array}{l}\text { 2-Hydroxypenta-2,4- } \\
\text { dienoate } \\
\text { hydratase }\end{array}$ & C211_RS10995 & CTCNB1_RS06905 (TesE) & RHA1_RS28310 (HsaE3) & Nov2c346 \\
\hline & $\begin{array}{l}\text { Acetaldehyde } \\
\text { dehydrogenase }\end{array}$ & C211_RS10985 & CTCNB1_RS06895 (TesG) & $\begin{array}{l}\text { RHA1_RS28315 } \\
\text { (HsaG3) }\end{array}$ & Nov2c344 \\
\hline & $\begin{array}{l}\text { 4-Hydroxy-2- } \\
\text { ketovalerate } \\
\text { aldolase }\end{array}$ & C211_RS10990 & CTCNB1_RS06900 (TesF) & RHA1_RS28320 (HsaF3) & Nov2c345 \\
\hline
\end{tabular}


Table 1. Cont.

\begin{tabular}{|c|c|c|c|c|c|}
\hline $\begin{array}{c}\text { Bile Acid Degradation } \\
\text { Pathway }\end{array}$ & Function & P. stutzeri Chol1 & C. testosteroni $\mathrm{CNB}-2 * * *$ & R. jostii RHA1 & $\begin{array}{l}\text { Sphingobium sp. } \\
\text { Strain Chol11 }\end{array}$ \\
\hline \multirow{4}{*}{$\begin{array}{l}\text { Transformation of } \\
12 \mathrm{OH}\end{array}$} & $\begin{array}{c}\text { 12 } \alpha \text {-Hydroxy-steroid } \\
\text { dehydrogenase }\end{array}$ & C211_RS11165 & CTCNB1_RS06490 (SteA) & unknown & Nov2c15 \\
\hline & $\begin{array}{l}\text { 12-Keto-steroid } \\
\text { hydrogenase }\end{array}$ & C211_RS11170 & CTCNB1_RS06495 (SteB) & unknown & Nov2c16 \\
\hline & $\begin{array}{c}12 \beta \text {-hydroxy steroid } \\
\text { dehydratase }\end{array}$ & C211_RS11175 (Hsh1) & CTCNB1_RS06500 (ORF7) & unknown & Nov2c12 \\
\hline & Steroid oxidoreducatse & C211_RS11180 (Sor1) & CTCNB1_RS06505 (ORF6) & unknown & Nov2c13 \\
\hline$\Delta^{4,6}$ variant & $\begin{array}{l}7 \alpha \text {-Hydroxysteroid } \\
\text { dehydratase }\end{array}$ & absent & absent & absent & Nov2c400 (Hsh2) \\
\hline
\end{tabular}

* Protein names from P. putida DOC21; ** genes located in cholesterol-degradation gene cluster of RHA1; *** characterized steroid degradation genes in C. testosteroni TA441 have been mapped to strain CNB-2 [24].

\subsection{Uptake of Bile Acids}

Bile acid substrates have to be transported into the cytoplasm before their complete mineralization. The knowledge about the transport of bile acids in bacteria is very limited. Below their critical micellar concentration, bile acids can passively enter the bacterial cell via trans-bilayer movement [53]. In their protonated, uncharged state, bile acids can undergo transverse diffusion across lipid membranes, in which the diffusion rate is determined by the number and position of the hydroxy groups on the steroid skeleton. In addition, bile acids can cross lipid membranes via transmembrane proteins. Deletion of ompF encoding a porin protein in an Escherichia coli strain resulted in a less susceptible phenotype towards the toxic effects of bile acids, suggesting that bile acids can pass across the membrane via protein channels like OmpF [54]. The membrane transport protein BaiG from the intestinal bile acid-dehydroxylating bacterium Clostridium scindens VPI12708 has proton-motiveforce-dependent bile acid uptake activity [55]. Heterologous expression of BaiG in E. coli causes increased uptake of cholic acid, chenodeoxycholic acid, and deoxycholic acid.

However, bile acid uptake and transport systems in bile acid-degrading bacteria are still largely unknown. In Sphingobium sp. strain Chol11, several TonB-dependent receptor proteins were more abundant in bile acid grown cells compared to glucose grown cells, suggesting that TonB-dependent receptors could be involved in bile acid uptake in this strain [23]. In support of this, a TonB-dependent receptor was recently shown to be involved in bacterial steroid transport in the $\alpha$-Proteobacterium Caenibius tardaugens NBRC16725 (formerly Novosphingobium tardaugens), in which a TonB deletion mutant showed reduced growth with estradiol [56]. Furthermore, it has been shown that expression of the porinencoding gene rjpA is upregulated in R. jostii RHA1 grown with cholic acid and that RjpA contributes to cholic acid uptake in this strain [57]. In addition, an ABC transporter encoded by cam $A B C D$ and an MFS transporter encoded by camM in strain RHA1 function in the uptake of cholic acid metabolites with an aromatized A-ring or with perhydroindane structures, respectively [43]. The ABC transporter system Mce4, which is involved in the trans-membrane transport of cholesterol and other hydrophobic sterols in steroiddegrading Actinobacteria, is not involved in the uptake of cholic acid [58,59].

\subsection{Oxidative Reactions at the A-Ring (Phase 1)}

Partial oxidation of the A-ring including oxidation of the 3-hydroxy group to a ketogroup and desaturation of the ring between $\mathrm{C} 1$ and $\mathrm{C} 2\left(\Delta^{1}\right)$ and between $\mathrm{C} 4$ and $\mathrm{C} 5\left(\Delta^{4}\right)$ are the first enzymatic steps during both aerobic and anaerobic degradation of bile acids (Figure 3) $[24,25,28,31,42]$. 


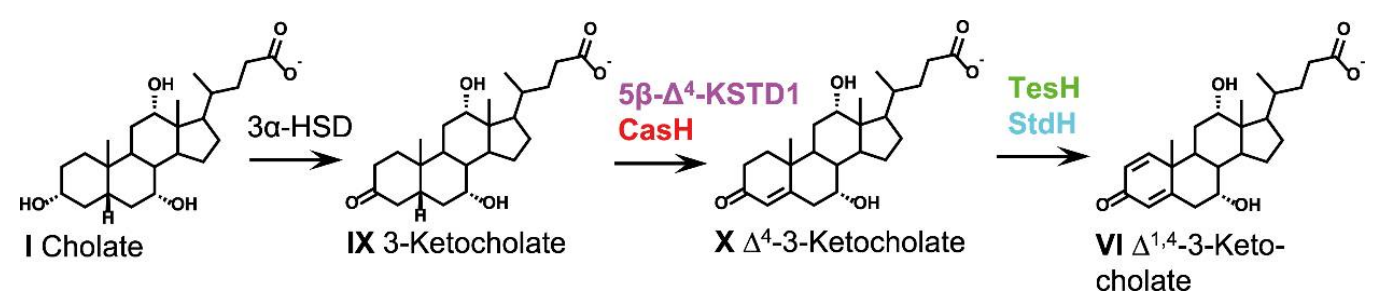

Figure 3. A-ring oxidation as phase 1 of bacterial bile acid degradation. For bile acids, the respective deprotonated bile salts are depicted. Text colors indicate the organism, in which the respective enzyme has been identified: light blue, P. putida DOC21; green, C. testosteroni TA441; red, $R$. jostii RHA1; magenta, Sphingobium sp. strain Chol11.

\subsection{1. $3 \alpha$-Hydroxysteroid Dehydrogenases}

The degradation of bile acids is initiated by $3 \alpha$-hydroxysteroid dehydrogenases ( $3 \alpha$ HSD), yielding 3-keto-bile acids. For the degradation of cholic acid (compound I), this reaction leads to 3-ketocholic acid (IX). 3 $\alpha$-HSDs belong to the short-chain dehydrogenase protein family (SDR) or aldo-keto reductase superfamily. Bacterial $3 \alpha$-HSDs are best studied in steroid-degrading $C$. testosteroni strains and have been shown to catalyze a bidirectional $\mathrm{NAD}(\mathrm{P})^{+} / \mathrm{NADP}(\mathrm{H})$-dependent oxidoreduction of $3 \alpha$-hydroxy- or 3-keto-groups of a variety of steroid substrates and of several other xenobiotic carbonyl compounds $[60,61]$. For $P$. stutzeri Chol1 and Sphingobium sp. strain Chol11, NAD ${ }^{+}$dependent $3 \alpha$-HSD activity has been detected in cell extracts with cholic acid $[26,40]$. The formation of 3-keto intermediates in other bile acid-degrading bacteria suggests that this step is conserved in aerobic and anaerobic bile acids degradation $[25,62]$. $3 \alpha$-HSDs are also found in bacteria, which cannot utilize steroids as growth substrates, e.g., P. aeruginosa [62,63].

\subsubsection{3-Ketosteroid Dehydrogenases}

Further oxidation of the A-ring is catalyzed by 3-ketosteroid dehydrogenases, which catalyze $\Delta^{1}$ - and $\Delta^{4}$-dehydrogenation reactions, introducing double bonds into the Aring. In the degradation of cholic acid, these reactions lead to $\Delta^{4}-3$-ketocholate $(X)$ and $\Delta^{1,4}$-3-ketocholate (VI).

Mammalian and many other bile acids have a bent steroid nucleus with rings A and $B$ in cis configuration and a $5 \beta$ conformation [1]. The respective $5 \beta$-3-keto bile acids produced by $3 \alpha$-HSDs are oxidized by $5 \beta$ - $\Delta^{4}-3$-ketosteroid dehydrogenases ( $5 \beta-\Delta^{4}$-KSTDs), which introduce $\Delta^{4}$ double bonds leading to a flat steroid nucleus. One $5 \beta-\Delta^{4}$-KSTD has been purified from $C$. testosteroni and was shown to oxidize steroids without or with a $C_{2}$ side chain [64]. Recently, $5 \beta-\Delta^{4}$-KSTD1 from Sphingobium sp. strain Chol11 has been shown to oxidize differently hydroxylated $5 \beta$ bile acid derivatives with and without side chain, but no $5 \alpha$ steroids, and CasH from $R$. jostii RHA1 was shown to have the same activity [42]. These enzymes are large flavoenzymes of the Old Yellow Enzyme family that can use quinones, phenazine methosulfate, 2,6-dichlorophenolindophenol, and $\mathrm{K}_{3} \mathrm{Fe}(\mathrm{CN})_{6}$ as electron acceptors, indicating that quinones could be the natural electron acceptors [42,64]. 5 $\beta-\Delta^{4}$-KSTD1 from Sphingobium sp. strain Chol11 contains FAD as well as FMN and an iron-sulfur cluster and is a very fast enzyme, which shows pronounced substrate inhibition $[42,65] .5 \beta-\Delta^{4}$-dehydrogenation activity has been detected in cell-free extracts of P. stutzeri Choll and Sphingobium sp. strain Choll1 with artificial electron acceptors $\mathrm{K}_{3} \mathrm{Fe}(\mathrm{CN})_{6}$ or phenazine methosulfate $[19,40]$. The formation of $\Delta^{1 / 4}$ - and $\Delta^{1,4}-3$ keto intermediates in other organisms confirms these steps for aerobic and anaerobic bile acids degradation $[18,19,24,36,40,41,43]$.

In contrast to $5 \beta$ steroids, $5 \alpha$ steroids have a planar steroid nucleus. $5 \alpha$ bile acids can be found in some fish, birds, or lizards [1]. $5 \alpha-\Delta^{4}$-3-ketosteroid dehydrogenases have been characterized in C. testosteroni (TesI) [66], R. jostii RHA1 (KstD) [67], and Rhodococcus erythropolis SQ1 (KstD4) [68] but have not been investigated in the context of bile acid degradation so far. 
A second double bond is introduced into the A-ring at $\mathrm{C} 1$ by $\Delta^{1}$-3-ketosteroid dehydrogenases [69]. Genes encoding these enzymes are found in diverse steroid-metabolizing bacteria. A $\Delta^{1}-3$-ketosteroid dehydrogenase for bile acid degradation is encoded by the gene stdH in Pseudomonas putida DOC21 [70]. The deletion mutant P. stutzeri Chol1 $\Delta k s t D 1$ accumulates compounds without a $\Delta^{1}$ double bond [42]. In C. testosteroni, the $\Delta^{1}$-3-ketosteroid dehydrogenase TesH is encoded directly adjacent to the $5 \alpha-\Delta^{4}-3$-ketosteroid dehydrogenase TesI [66,71]. Steroid-degrading Actinobacteria often encode several isoenzymes of $\Delta^{1}$-3-ketosteroid dehydrogenases [72-74]. Two genes (kstD3 and kstD3b), located in the cholic acid degradation gene cluster of $R$. jostii RHA1, encode putative $\Delta^{1}$-3-ketosteroid dehydrogenases [28]. The crystal structure of the 3-ketosteroid $\Delta^{1}$-dehydrogenase from R. erythropolis SQ1 revealed a flavin adenine dinucleotide (FAD)-binding site [75]. The dehydrogenation mechanism mediated by $\Delta^{1}$-dehydrogenases is based on the trans-axial removal of the $\mathrm{C} 1(\alpha)$ and $\mathrm{C} 2(\beta)$ hydrogen atoms [75-77].

\subsection{Side-Chain Degradation (Phase 2)}

The side chains of bile acids are generally degraded in a stepwise fashion resembling in large parts $\beta$-oxidative reaction sequences similar to the sterol side chain degradation pathway (Figure 4). Nevertheless, some key reactions for the degradation of bile acid side chains are different from this canonical progression and vary among the different model organisms. In contrast to the degradation of the aliphatic sterol side chain, the carboxylic bile acid side chain does not need to be oxidized prior to degradation. Thus, the complete removal of the bile acid side chain is possible without elemental oxygen as a co-substrate and side-chain degradation under aerobic and anaerobic conditions seems to follow the same progression $[19,25]$. In contrast to bile acid degraders from the $\beta$ - and $\gamma$-Proteobacteria and Actinobacteria, bile acid-degrading $\alpha$-Proteobacteria from the Sphingomonadacea family do not encode the majority of side-chain degradation proteins known from other model organisms. These bacteria seem to have evolved a different progression for side-chain degradation, which is catalyzed by yet unknown enzymes $[23,41,78]$ (preprint).

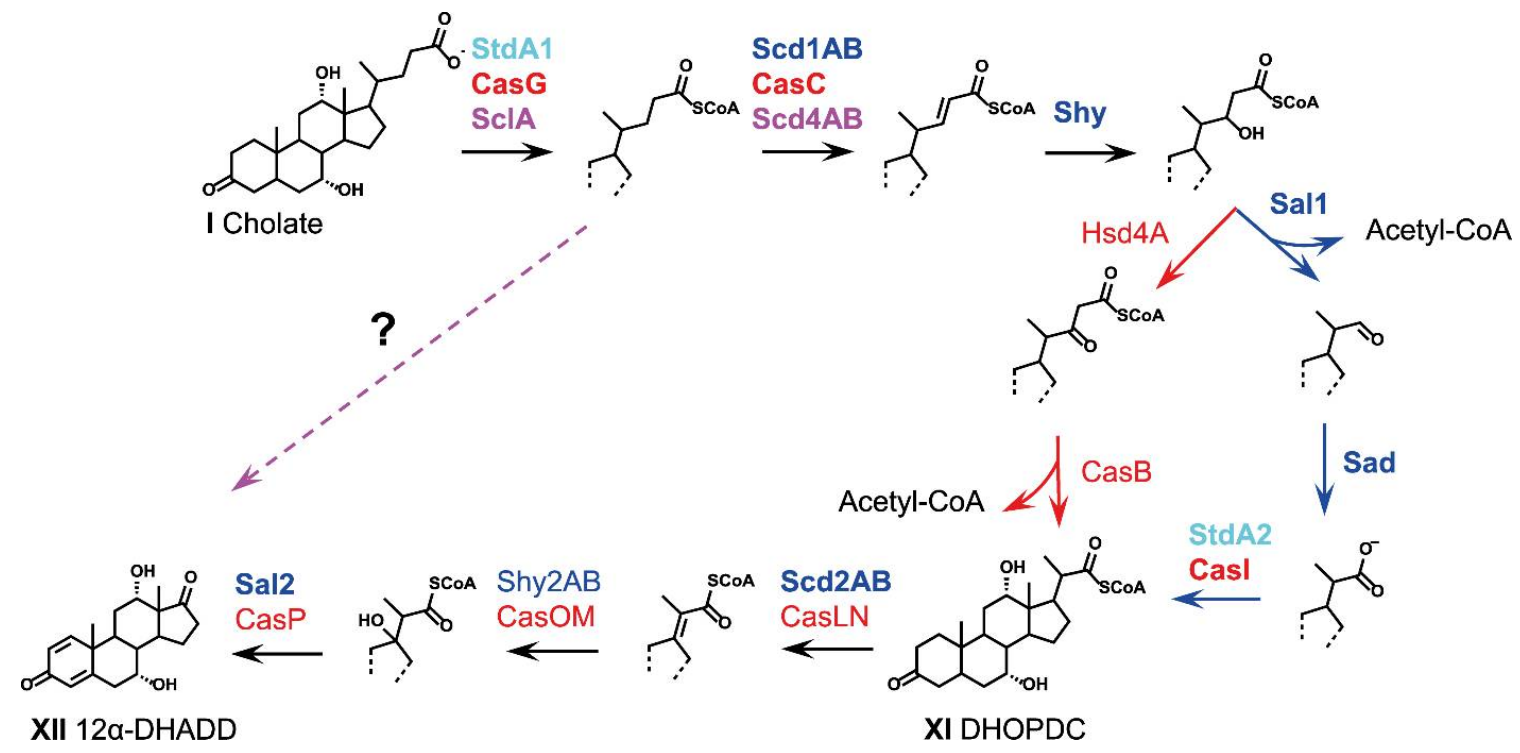

Figure 4. Degradation of the carboxylic $C_{5}$ side chain as phase 2 of bacterial bile acid degradation. For bile acids, the respective deprotonated bile salts are depicted. Text and arrow colors indicate the organism, in which the respective enzyme has been identified: dark blue, P. stutzeri Chol1; light blue, P. putida DOC21; green, C. testosteroni TA441; red, R. jostii RHA1; magenta, Sphingobium sp. strain Chol11; black arrows, found in several organisms; dotted magenta arrow, so far unknown side-chain degradation pathway in Sphingobium sp. strain Chol11 and other Sphingomonadaceae. Abbreviations: DHOPDC, 7,12-Dihydroxy-3-oxo-pregna-1,4-diene-carboxylic acid; $12 \alpha$-DHADD, $7 \alpha, 12 \alpha$-Dihydroxy-androsta-1,4-diene-3,17-dione. 


\subsubsection{Cleavage of Conjugated Bile Acids}

Prior to excretion into the duodenum, bile acids are conjugated with the amino acids glycine or taurine via amide bonds to enhance solubility [4]. Many intestinal, non-bile aciddegrading bacteria are able to deconjugate these bile acid amides using bile salt hydrolases (Bsh) [6,79]. Additionally, several bile acid-degrading bacteria have also been reported to utilize these conjugated bile acids as growth substrates: While $C$. testosteroni strains such as KF-1 are able to utilize the complete taurocholate molecule, Pseudomonas and Rhodococcus strains were described to only degrade the bile acid moiety after cleaving the amide bond of taurocholate [80]. Similarly, Sphingobium sp. strain Chol11 is able to grow with both glycocholate and taurocholate, but not with the free amino acids taurine and glycine [23]. The bile acid amidase Bsa from strain Chol11 was shown to cleave both conjugated bile acids and was present in higher abundances during growth with bile acids. Interestingly, this enzyme is significantly different from the well-known bile salt hydrolase enzymes in intestinal bacteria [81].

\subsubsection{Coenzyme-A Activation}

In analogy to the $\beta$-oxidation of fatty acids, coenzyme A (CoA) activation of the carboxylic group of free bile acids is the initial side-chain degradation step [26,35,41]. StdA1, a CoA-ligase encoded in the bile acid degradation gene cluster of P. putida DOC21 converted cholic acid and the degradation intermediates 3-ketocholic acid (IX), $\Delta^{1 / 4}-3$-ketocholic acid (e.g., X) and $\Delta^{1,4}$-3-ketocholic acid (VI) into the corresponding CoA-thioesters, while it did not activate bile acid derivatives with a $C_{3}$ side chain [35]. An ortholog of StdA1, CasG, encoded in the cholic acid degradation gene cluster of $R$. jostii RHA1, showed analogous substrate preferences towards $C_{5}$ bile acids side chains $[28,82]$. In cell extracts of $P$. stutzeri Chol1, both, cholic acid and $\Delta^{1,4}-3$-ketocholic acid can be activated with CoA [26] and deletion of the stdA1 homolog in this strain inhibits side-chain degradation [42]. A homolog of StdA1 was also identified in the bile acid degradation gene cluster of Azoarcus sp. strain Aa7 [25], and a CoA-ligase with high specificities for the activation of $C_{5}$ carboxylic side chains was characterized in the cholesterol degrading $\beta$-Proteobacterium Sterolibacterium denitrificans [83], suggesting that CoA-ligation is also the first step of bile acid degradation under anaerobic conditions.

While the length of the side chain appears to be the determining factor for the substrate preferences of StdA1 and CasG, the configuration of the steroid nucleus seems to be less important. In contrast, the $\mathrm{C}_{5}$ side chain CoA-ligase SclA from Sphingobium sp. strain Chol11 preferentially activates bile acid derivatives with oxidized A- and B-rings with a 3-keto- $\Delta^{4}$ - or 3-keto- $\Delta^{4,6}$-structure (e.g., XIV) [41] further supporting the presence of a distinct pathway among the Sphingomonadaceae.

\subsection{3. $\alpha, \beta$-Dehydrogenation}

Following CoA-activation, a double bond is introduced into the side chain by acylCoA-dehydrogenases (ACADs). In P. stutzeri Chol1, this $\alpha, \beta$-dehydrogenation reaction is catalyzed by Scd1AB [84]. Scd1A and Scd1B are encoded by two adjacent genes and have been suggested to form a $\alpha_{2} \beta_{2}$-heterotetrameric structure based on comparisons with other steroid ACADs. This unprecedented $\alpha \beta$-dehydrogenase architecture was initially identified in the two heteromeric ACAD complexes ChsE4/5 and ChsE1/2 in Mycobacterium tuberculosis $\mathrm{H} 37 \mathrm{Rv}$, which function in the $\alpha, \beta$-dehydrogenation of $\mathrm{C}_{8}$ and $\mathrm{C}_{3}$ side-chain CoA-esters during cholesterol degradation $[85,86]$. In these specialized ACADs, the heterotetrameric form is essential for catalytic activity. Only one of the subunits in each $\alpha \beta$-heterodimer contains a conserved, catalytically active glutamate residue and binding of one FAD co-factor occurs at the dimer interface. Thus, each $\alpha_{2} \beta_{2}$-heterotetramer contains two active sites and two FAD-binding sites. The $\alpha_{2} \beta_{2}$-heterotetrameric structure was confirmed for a bile acidspecific ACAD in the bile acid-degrading thermophilic Actinobacterium Thermomonospora curvata, which showed substrate preferences for $C_{3}$ over $C_{5}$ side chains [87]. 
The steroid ACAD CasC from R. jostii RHA1 was shown to catalyze side chain $\alpha, \beta$ dehydrogenation of the CoA-esters of cholic acid, deoxycholic acid, and 3 $\beta$-hydroxy-5-enecholic acid but not of derivatives with shorter side chains [88]. CasC consists of two fused ACAD domains, of which only the C-terminal domain contains the catalytic glutamate base, while the N-terminal domain is required for FAD co-factor binding.

The genome of Sphingobium sp. strain Chol11 does not encode orthologs of CasC or Scd1AB based on reciprocal BLASTp analyses [41]. However, the enzyme complex Scd4AB, which has high similarities to ACADs involved in the degradation of the steroid nucleus, also catalyzes $\alpha, \beta$-dehydrogenation of the $C_{5}$ side chain [78] (preprint).

\subsubsection{Hydroxylation of the Double Bond}

The $\alpha \beta$-double bond is subsequently hydrated by enoyl-CoA-hydratases, forming $\beta$-hydroxyacyl-CoA-thioesters. In P. stutzeri Chol1, the respective $\Delta^{22}$-enoyl-CoA hydratase is encoded by shy1 [34]. Shy1 contains a C-terminal hot-dog-fold domain, which is also found in $(R)$-specific enoyl-CoA hydratases catalyzing the hydration of trans-2-enoyl-CoA to (R)-3-hydroxyacyl-CoA [89]. Homologs of Shy1 have been identified in P. putida DOC21 and several C. testosteroni strains [34,35], but are missing in Sphingobium sp. strain Chol11 and related bile-acid degrading Sphingomonadaceae. In $R$. jostii RHA1, the gene casD located adjacent to cas $C$ in the cholic acid degradation gene cluster was predicted to encode a $\mathrm{C}_{5}$ side chain enoyl-CoA-hydratase [28] and expression of casD was upregulated in the presence of cholic acid [90]. Nevertheless, the function of this gene has still to be confirmed.

\subsubsection{Release of Acetyl-CoA and Formation of $\mathrm{C}_{3}$-Carboxylic Side Chains}

During fatty acid degradation, the corresponding $\beta$-hydroxy group is typically oxidized to a $\beta$-keto group. Subsequent thiolytic cleavage releases acetyl-CoA, thus producing a shortened CoA-activated fatty acid. Similarly, the release of acetyl-CoA from $\mathrm{C}_{5} \beta$ hydroxy side chain degradation intermediates seems to be a general theme during bile acid degradation. Accordingly, analysis of the wild type and mutant strains of P. stutzeri Chol1 [26], R. jostii RHA1 [43], and C. testosteroni TA441 [36] revealed that carboxylic $C_{3}$ side chain intermediates such as 7,12-dihydroxy-3-oxo-pregna-1,4-diene carboxylic acid (DHOPDC, XI) for cholate are formed in all these organisms. This was also shown for anaerobic and aerobic cultures of Azoarcus sp. strain Aa7 growing with cholic acid (Yücel et al., 2018).

In Proteobacteria, the deacetylation of the carboxyl side chain differs from the expected thiolytic cleavage known from conventional $\beta$-oxidation of carboxylic acids. Instead, this reaction proceeds via an aldolytic cleavage of acetyl-CoA from the $\mathrm{C}_{5}$ side chain yielding a free aldehyde as a product [33]. This was first identified in P. stutzeri Chol1, and the gene product of sal1 was shown to catalyze the respective aldolytic cleavage reaction [34]. Sal1 shows similarities to the SCP-x-type thiolase family, but lacks a catalytically active $\mathrm{N}$-terminal cysteine, which is highly conserved in catabolic thiolases [91] due to its requirement for a nucleophilic attack on the respective $\beta$-keto groups allowing subsequent addition of CoA. Homologs of Sal1 are also encoded in the respective bile acid degradation gene clusters of P. putida DOC21, C. testosteroni, and Azoarcus sp. strain Aa7, suggesting that acetyl-CoA is removed by an analogous aldolytic cleavage reaction in these strains $[25,34]$. No homologs of Sal1 are encoded in the genomes of Sphingobium sp. strain Chol11 [41] or $R$. jostii RHA1. However, the cholic acid degradation gene cluster of strain RHA1 encodes CasB [28], a homolog of the cysteine-containing thiolase FadA5, which catalyzes a thiolytic cleavage reaction of acetyl-CoA from $\mathrm{C}_{5}$ side-chain degradation intermediates of cholesterol in M. tuberculosis H37Rv [92,93]. The catalytically active cysteine of typical thiolases is also conserved in $\mathrm{CasB}$, indicating that acetyl-CoA is thiolytically cleaved during bile-acid degradation in strain RHA1 [28].

In $P$. stutzeri Choll, the $\mathrm{C}_{3}$ side chain aldehyde product is further oxidized to the corresponding carboxylic acid by an $\mathrm{NAD}^{+}$-dependent steroid aldehyde dehydrogenase encoded by the gene sad [34]. In the degradation of cholic acid, this reaction leads to 
DHOPDC (XI). Homologs of Sad are also encoded in the bile acid degradation gene clusters of P. putida DOC21, C. testosteroni, and Azoarcus sp. strain Aa7 [25,34], while no homologs of Sad exist in proximity to the cholic acid degradation gene cluster of $R$. jostii RHA1 or in the genome of Sphingobium sp. strain Chol11 and related bile-acid degrading Sphingomonadaceae.

An aldolytic cleavage of acetyl-CoA during bile acid degradation is unexpected because thiolysis mediated by a $\beta$-keto intermediate is structurally possible with $\mathrm{C}_{5}$ side chains. In addition, thiolysis would save energy because a subsequent ATP-dependent CoA-activation of the resulting $C_{3}$ side chain is not necessary. Nevertheless, an aldolytic cleavage seems to be the primary reaction mechanism in bile acid-degrading $\beta$ - and $\gamma$-Proteobacteria.

\subsubsection{Release of Propionyl-CoA and Formation of Androstadienediones (ADDs)}

Further side-chain degradation follows a similar progression, leading to the release of propionyl-CoA and the formation of $\mathrm{C}_{19}$ steroids. In $\beta$ - and $\gamma$-Proteobacteria, the first step is the CoA-activation of the $\mathrm{C}_{3}$ carboxylic side chain. The steroid CoA-synthetase StdA2, specific for activating carboxylic $\mathrm{C}_{3}$ side chain intermediates has been identified in P. putida DOC21 [35]. ATP-dependent CoA-activation of a cholic acid degradation intermediate with a $\mathrm{C}_{3}$ side chain has been measured in cell extracts of P. stutzeri Chol1 [26]. In $R$. jostii RHA1, the acyl-CoA-synthetase CasI encoded in the cholic acid degradation gene cluster of $R$. jostii RHA1 specifically activates steroid $C_{3}$ side chains [28,94]. A homolog of StdA2 was also identified in the bile acid degradation gene cluster of Azoarcus sp. strain Aa7 and a CoA-ligase specifically activating $C_{3}$ carboxylic side chains was characterized in Sterolibacterium denitrificans $[25,83]$, suggesting that CoA-ligation of $C_{3}$ carboxylic side chains also occurs under anaerobic conditions.

A distinct gene cluster encoding a heteromeric ACAD, a heteromeric enoyl-CoAhydratase, and an aldolase, which together catalyze the remaining $C_{3}$ side-chain degradation steps, seems to be conserved with similar gene synteny throughout most steroid side chain-degrading organisms [95], including P. stutzeri Chol1, C. testosteroni CNB-2, and $R$. jostii RHA1. The next step in the degradation of the $C_{3}$ side chain of bile acids after CoA-activation is a dehydrogenation reaction catalyzed by a heteromeric ACAD belonging to the same family as the $C_{5}$ side chain ACADs described above. The heteromeric character of these $C_{3}$ side chain-specific ACADs was first identified in the ACAD complex ChsE1/2, which catalyzes a homologous reaction during cholesterol side-chain degradation in $M$. tuberculosis [96]. Homologs of chsE1 and chsE2 are also encoded in the bile acid degradation gene clusters of P. stutzeri Chol1, C. testosteroni CNB-2, and R. jostii RHA1. A transposon mutant of the $\alpha$-subunit of the respective ACAD in P. stutzeri Chol1 (Scd2AB) was unable to degrade $C_{3}$ side chain intermediates during cholic acid degradation [26].

The resulting double bond is subsequently hydrated, followed by the release of propionyl-CoA by a retro-aldol reaction as proposed by [97]. These reactions are catalyzed by a protein complex formed between a heteromeric enoyl-CoA-hydratase and a single aldolase in the bile acid-degrading Actinobacterium T. curvata [98] and during cholesterol side-chain degradation in $M$. tuberculosis $[95,99,100]$. The heteromeric enoyl-CoA-hydratase consists of two subunits, which both carry MaoC-like domains, and the $\alpha$-subunit carries an additional DUF35 domain. The hydration of the $C_{3}$ side chain double bond was shown to have an unfavorable equilibrium, which was overcome when the hydrated product was removed by the aldolase protein [95]. It was further shown that the aldolase associates with the DUF35 domain of the $\alpha$-subunit of the heteromeric hydratase complex [95,100]. In P. stutzeri Chol1, the aldolase Sal2 is essential for the latter reaction step [84]. During the degradation of cholic acid, a sal2 deletion mutant accumulated a $\mathrm{C}_{3}$ side chain derivative with a double bond and one with a hydroxy group at C17 in minor amounts. This agrees with the notion, that the side chain hydration reaction requires the presence of the aldolase protein to proceed to completion. Like the Sal1 protein, Sal2 and its homologs in R. jostii RHA1, T. curvata, and M. tuberculosis do not harbor the catalytically active cysteine residue 
known from thiolases. Here, however, the tertiary hydroxy group formed during $C_{3}$ side chain hydration precludes oxidation to a keto group and subsequent thiolytic cleavage of propionyl-CoA.

No homologs of $C_{3}$ side-chain degradation enzymes, including Sal1, FadA5, Sad, or Sal2/Ltp2 were found in Sphingobium strain Chol11 and related bile-acid degrading Sphingomonadaceae., further supporting an alternative side-chain degradation pathway [23,41,78] (preprint).

A-ring oxidation and side-chain degradation result in the formation of androsta-1,4diene-3,17-diones (ADDs), which represent key intermediates in bile acid, cholesterol, and testosterone degradation. In the degradation of cholic acid, the removal of the $\mathrm{C}_{3}$ side chain leads to $7 \alpha, 12 \alpha$-dihydroxy-androsta-1,4-diene-3,17-dione (12 $\alpha$-DHADD, XII). The respective aerobic and anaerobic degradation pathways for ADDs are in large parts identical for bile acid, testosterone, and cholesterol degradation.

\subsection{Aerobic Cleavage of the Steroid Skeleton via the 9,10-Seco Pathway (Phase 3a)}

\subsection{1. $9 \alpha$-Hydroxylation: Opening of the B-Ring}

Aerobic degradation of ADDs is initiated by hydroxylation at the $\mathrm{C} 9$ atom of ring $\mathrm{B}$ which is catalyzed by 3-ketosteroid $9 \alpha$-hydroxylases (Figure 5A) [46]. The resulting 3-keto$\Delta^{1,4}-9 \alpha$-hydroxy intermediate is unstable and reacts in a spontaneous retro-aldol reaction opening ring $\mathrm{B}$ between $\mathrm{C} 9$ and $\mathrm{C} 10$, which is driven by concomitant aromatization of the A-ring [101]. In the degradation of cholic acid, this reaction leads to 3,7,12-trihydroxy-9,10seco-androsta-1,3-5(10)-triene-9,17-dione (THSATD, XIII).

3-ketosteroid $9 \alpha$-hydroxylases have mainly been characterized in Actinobacteria and are monooxygenases composed of a terminal oxygenase and a reductase, which are encoded by $k s h A$ and $k s h B$, respectively $[46,102]$. The Rieske oxygenase KshA contains a non-heme mononuclear iron and an iron-sulfur cluster and catalyzes substrate $9 \alpha$-hydroxylation. KshB is a ferredoxin reductase, which oxidizes NADH and transfers the electrons through a flavin co-factor and a plant-type iron-sulfur cluster to the iron-sulfur cluster of KshA [103].
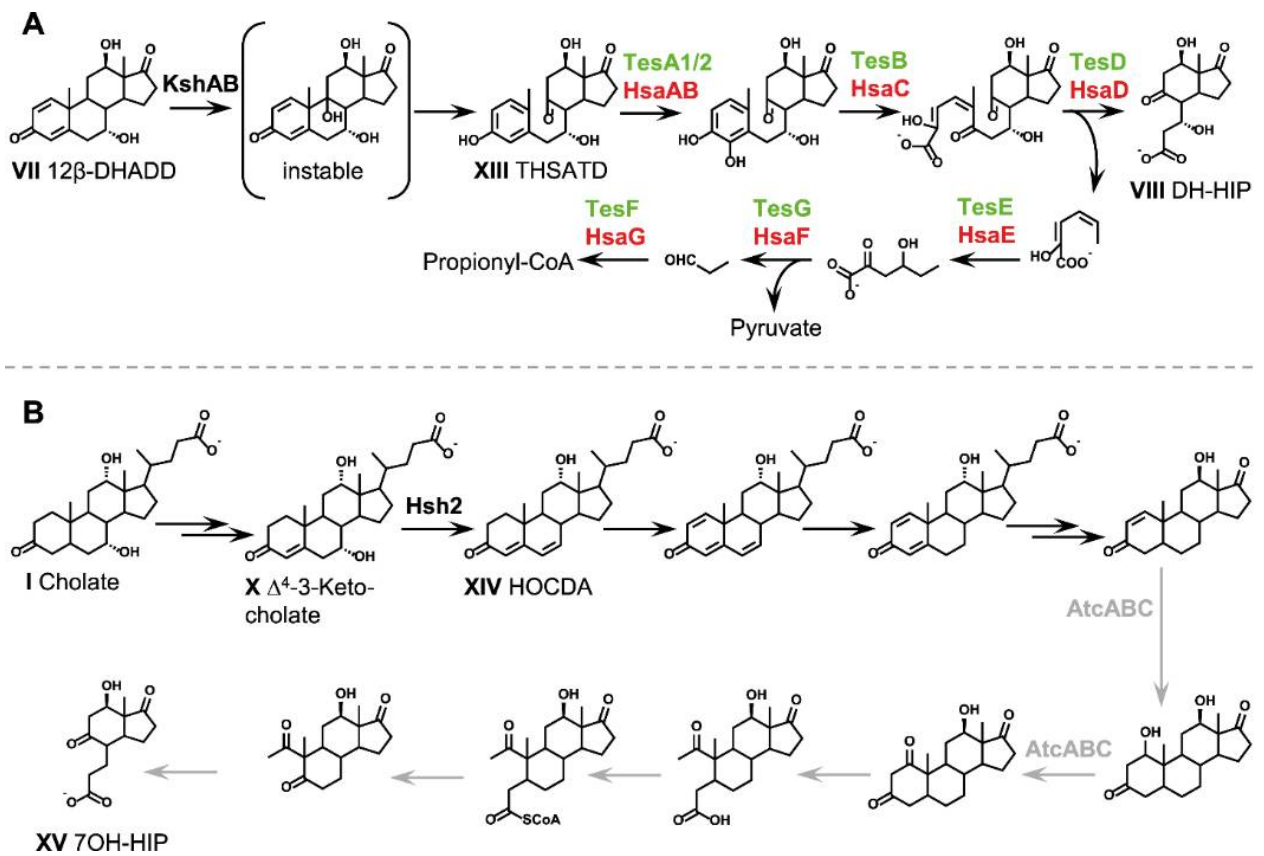

Figure 5. Cleavage of rings $\mathrm{A}$ and $\mathrm{B}$ as well as degradation of the A-ring as phase 3 of bacterial bile acid degradation. (A) Aerobic degradation via the 9,10-seco pathway. Text colors indicate the organism, in which the respective enzyme has been identified: dark blue, P. stutzeri Chol1; light blue, P. putida DOC21; green, C. testosteroni TA441; red, R. jostii RHA1; magenta, Sphingobium sp. strain Chol11; black, identified in several organisms. (B) Anaerobic degradation via the 2,3-seco pathway. Colors: black, described for Azoarocus sp. strain Aa7; grey, as inferred from anaerobic degradation of cholesterol and testosterone. For bile acids, the respective deprotonated bile salts are depicted. Abbreviations: HOCDA, 12 $\alpha$-Hydroxy-3-oxo-4,6-choldienoic acid; 7OH-HIP, 7-Hydroxy-H-methyl-hexahydro-indanone-propanoate. 
Steroid-degrading Rhodococcus spp. typically encode several KshA isoenzymes with different affinities towards 3-keto steroid substrates [104]. In R. rhodochrous DSM43269 and $R$. jostii RHA1, one distinct $k s h A$ gene is upregulated during growth with cholic acid and its deletion abolishes cholic acid degradation indicating its essential and specific role in bile acid degradation $[28,104,105]$. The respective KshA isoenzyme in $R$. jostii RHA11 preferentially catalyzes the hydroxylation of cholic acid degradation intermediates that still carry a $C_{5}$ or $C_{3}$ side chain indicating that side chain and $A / B$-ring degradation proceed simultaneously in Actinobacteria [105].

In contrast to that, $9 \alpha$-hydroxylation in the bile acid-degrading Proteobacteria $P$. stutzeri Chol1 and $C$. testosteroni TA441 only occurs after complete side chain removal and requires the isomerization of the $12 \alpha$-hydroxy group into a $\beta$-hydroxy group in 12 -hydroxy bile acids $[33,37]$ (see below). In P. stutzeri Chol1, the end product of cholic acid side chain degradation is transformed into the respective 9,10-seco steroid via an oxygenase-dependent reaction step [19]. A $k s h A_{C h o l 1}$ deletion mutant strain transforms bile acids to their respective hydroxylated ADDs and shows diminished growth with bile acid substrates [78] (preprint). Additionally, heterologously produced $\mathrm{KshAB}_{\mathrm{Chol} 1}$ hydroxylated a variety of differently hydroxylated ADDs, but no compounds with side chains. In Sphingobium sp. strain Chol11, formation of seco-steroids from cholic acid was not observed in the medium of wild-type cultures growing with cholic acid, but the strain encodes five homologs of KshA, three of which were detected in a proteome study in cells adapted to steroid substrates. These had low activity towards bile acid degradation intermediates with a $\Delta^{4,6}$-structure $[23,41,78]$ (preprint). Interestingly, neither Sphingobium sp. strain Chol11 [41,78] (preprint) nor the steroid-degrading C. tardaugens NBRC16725 [106] seems to encode distinct homologs of the reductase compound $\mathrm{KshB}$, which might indicate an alternative electron shuttling mechanism in these strains.

\subsubsection{Opening and Hydrolysis of the A-Ring}

Further degradation of 9,10-seco steroids is initiated by reactions that are well known from the aerobic degradation of aromatic compounds [107]. The aromatized A-ring is first hydroxylated at C4 leading to vicinal hydroxy groups as in catechol, which is a central intermediate in the aerobic degradation of aromatic compounds. This hydroxylation is catalyzed by two-component flavin-dependent monooxygenases [47]. In C. testosteroni, the enzymes are encoded by tes $A 1$ and tes $A 2$ [108]. R. jostii RHA1 encodes several isoenzymes of the respective monooxygenase subunits $\mathrm{HsaA}$ and $\mathrm{HsaB}$, but only the corresponding genes located in the cholic-acid degradation gene cluster were upregulated during growth with cholic acid [28].

In the next step, the aromatic ring is subject to meta-cleavage between C4 and C5 converting the former A-ring into a 2-hydroxy-6-keto-carboxylic acid [97]. This cleavage is catalyzed by TesB in C. testosteroni [109] and by HsaC in steroid-degrading Actinobacteria $[110,111]$. HsaC is a type-I extradiol dioxygenases with a non-heme $\mathrm{Fe}^{2+}$ at the catalytic site. The HsaC paralog encoded in the cholic-acid degradation gene cluster of strain RHA1 is upregulated during growth with cholic acid [28].

Further cleavage of a 2-hydroxy-hexa-2,4-dienoate moiety from the opened A-ring leads to the formation of perhydroindane derivatives (3a $\alpha-H-4 \alpha$ (3-propanoate)-7a $\beta$ methylhexahydro-1,5-indandione (HIPs)) consisting of the former C- and D-rings with a $C_{3}$ carboxylic side chain derived from the former B-ring. In cholic acid degradation, this reaction leads to a $7 \beta, 3^{\prime} \alpha$-dihydroxy derivative of HIP (DH-HIP, VIII). The respective hydrolase is encoded by tes $D$ in C. testosteroni [112], and by $h s a D$ in steroid-degrading actinomycetes [111]. HsaD is a meta-cleavage product hydrolase of the $\alpha, \beta$-hydrolase superfamily [113-115].

The 2-hydroxy-hexa-2,4-dienoate is further degraded via 4-hydroxy-2-oxohexanoate to pyruvate and propionyl-CoA [116]. tesEFG and $h s a E F G$ encode the enzymes catalyzing the degradation of 2-hydroxy-hexa-2,4-dienoate in C. testosteroni and M. tuberculosis, re- 
spectively $[66,111,116,117]$. The $h s a E F G$ homologs in the bile-acid degradation gene cluster in $R$. jostii RHA1 were upregulated with cholate as substrate.

Homologs of all key enzymes required for the metabolism of the A/B-ring are also found in the cholic acid degradation gene clusters of P. stutzeri Chol1, Sphingobium sp. strain Chol11 and Azoarcus sp. strain Aa7 [23,41,84].

\subsection{Anaerobic Cleavage of the Steroid Skeleton via the 2,3-Seco Pathway (Phase 3b)}

In contrast to the complete anaerobic degradation of sterols and testosterone, which has been reported for a number of denitrifying Proteobacteria [41,118-121], complete degradation of bile acids in the absence of elemental oxygen has only been reported for Azoarcus sp. strain Aa7 [25]. Genomic, biochemical, and physiological analyses suggested that strain Aa7 uses the oxygen-independent 2,3-seco pathway for the anaerobic degradation of the steroid nucleus (Figure 5B), which was first described for the anaerobic degradation of cholesterol and testosterone in Sterolibacterium denitrificans [50,120,122], Steroidobacter denitrificans $[119,123]$ and Thauera [121].

The 2,3-seco pathway is initiated by a yet unknown enzyme that catalyzes the reduction of the $\Delta^{4}$-double bond of the ADD substrate. The next steps are catalyzed by the bifunctional molybdopterin-containing hydratase/dehydrogenase protein complex Atc $A B C$, which adds a water molecule to the $\Delta^{1}$-double bond of the A-ring at $\mathrm{C} 1$ and subsequently oxidizes the hydroxy group into a keto group [49,124]. Homologs of AtcABC with high similarities to the characterized proteins from Stl. denitrificans are encoded in the bile acid degradation gene cluster of strain Aa7 [25]. A so far unknown enzyme catalyzes an oxygen-independent opening of the A-ring resulting in the formation of the 2,3-seco intermediate 1,17-dioxo-2,3-seco-androstan-3-oic acid (DSAO) [49,123]. A derivative of this compound was also identified in culture supernatants of strain Aa7 growing with cholate under denitrifying conditions [25]. After CoA-activation of this compound, acetyl-CoA is removed via a retro-aldol cleavage [49], before the B-ring is cleaved by so far unknown reactions. This leads to the formation of perhydroindane derivatives (HIPs) as in the aerobic 9,10-seco pathway. Thus, the aerobic and anaerobic bile acid degradation pathways converge at the stage of HIP. Azoarcus sp. strain Aa7 is able to grow with cholic, chenodeoxycholic, and deoxycholic acid under aerobic and anaerobic conditions, and its genome encodes both the 9,10-seco- and the 2,3-seco pathway for ADD degradation [25]. Interestingly, this strain requires the activity of the $7 \alpha$-hydroxysteroid dehydratase Hsh2 (see below) to be able to channel $7 \alpha$-hydroxy bile acids into the 2,3-seco pathway under anaerobic conditions. A hsh 2 gene deletion mutant accumulated 12 $\beta$-DHADD (VII) as end products of bile acid degradation under anaerobic conditions from the $7 \alpha$-hydroxy bile acids cholic and chenodeoxycholic acid.

\subsection{C/D-Ring Degradation (Phase 4)}

Degradation of rings $\mathrm{A}$ and $\mathrm{B}$ leads to the formation of perhydroindane derivatives (HIPs) consisting of former rings $\mathrm{C}$ and $\mathrm{D}$ with a carboxylic $\mathrm{C}_{3}$ side chain derived from former ring $\mathrm{B}$. A gene cluster encoding HIP degradation is conserved in steroid-degrading bacteria (Table 1) suggesting a canonical HIP-degradation pathway for cholesterol, testosterone, and bile acids (Figure 6) $[24,27,28,32,49,125]$. This is further supported by the fact, that genes required for C/D-ring degradation are only found in the cholesterol degradation cluster in sterol and bile acid-degrading Actinobacteria, but not in the respective bile acid degradation cluster [28]. 

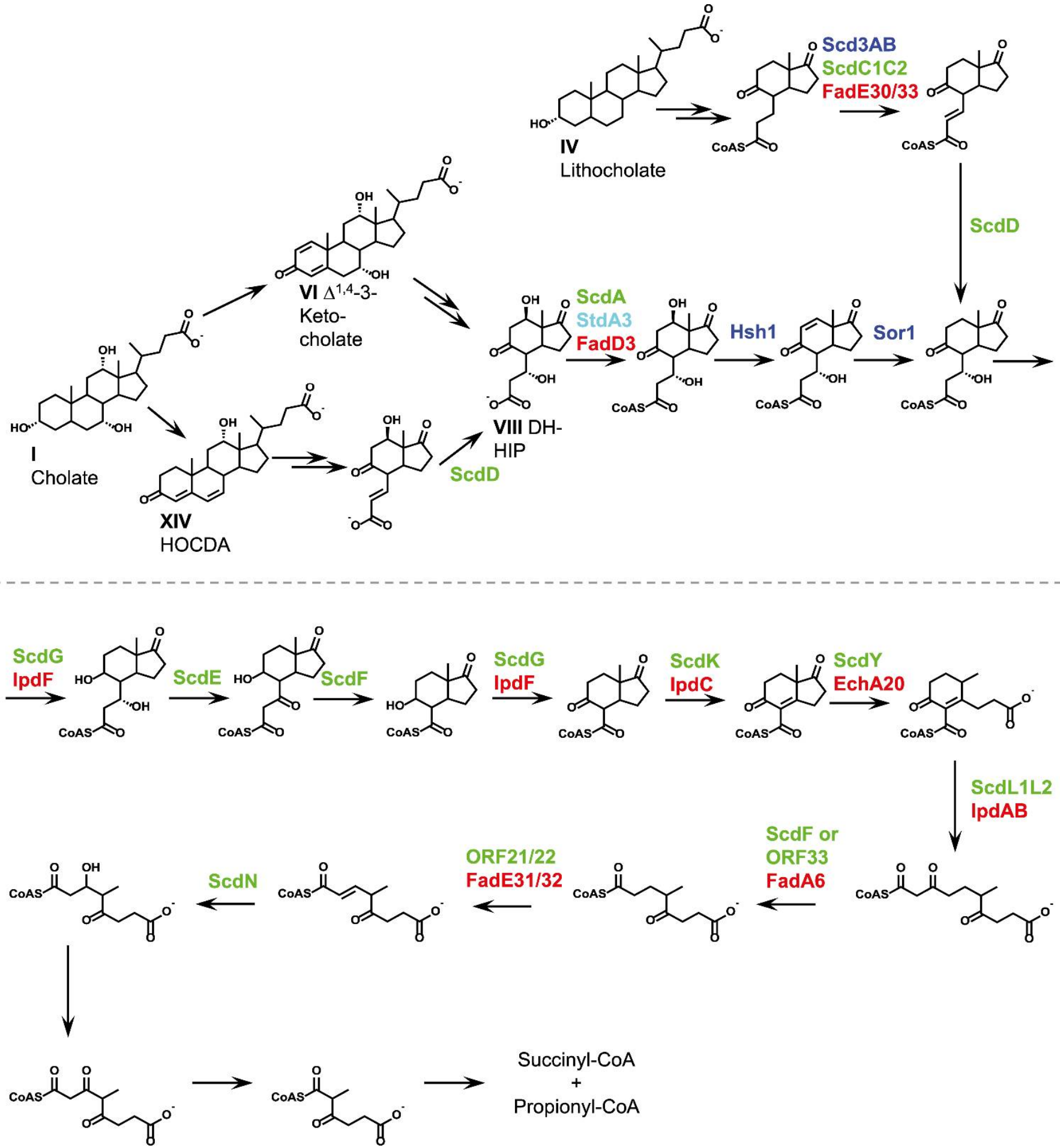

Figure 6. Degradation of H-methyl-hexahydro-indanone-propanoate (HIP) derivatives as phase 4 of bacterial bile acid degradation and channeling of differently hydroxylated bile acids into one common pathway via $\Delta^{1,4}$-3-keto intermediates or $\Delta^{4,6}$-intermediates. For bile acids, the respective deprotonated bile salts are depicted. Text colors indicate the organism, in which the respective enzyme has been identified: dark blue, P. stutzeri Chol1; light blue, P. putida DOC21; green, C. testosteroni TA441; red, R. jostii RHA1; magenta, Sphingobium sp. strain Chol11.

HIP degradation is initiated by CoA-activation of the $\mathrm{C}_{3}$-side chain. In P. putida DOC21 [35], C. testosteroni TA441 [38] and R. jostii RHA1 [82], HIP CoA-ligases are encoded by the genes $s t d A 3$, fadD3, and $s c d A$, respectively. After activation with $C o A$, the side chain is further degraded via a $\beta$-oxidation-like reaction sequence [39]. In bile acid degradation, 
this reaction sequence can depend on the organism and on the hydroxylation pattern of the bile acid substrate, which is discussed in more detail below. In general, the side chain of HIP-CoA is dehydrogenated by heterotetrameric ACADs similar to the ones involved in steroid side-chain degradation [126]. In P. stutzeri Chol1 and C. testosteroni TA441, these ACADs are encoded by the genes $s c d 3 A / s c d 3 B$ and $s c d C 1 / s c d C 2$, respectively $[84,127]$. The resulting double bond has been suggested to be hydrated by an enoyl-CoA hydratase, followed by dehydrogenation of the resulting hydroxy group [36,125]. In C. testosteroni TA441 the genes $s c d D$ and $s c d E$, encoding an enoyl-CoA hydratase and a 3-hydroxylacyl CoA-dehydrogenase have been shown to be involved in these reactions [39]. Subsequently, an acetyl-CoA moiety is removed from the side chain [125]. This reaction is presumably catalyzed by a 3-ketoacyl-CoA transferase in C. testosteroni TA441 encoded by the gene $s c d F$ [39]. Homologs of these genes are also encoded in the HIP-degradation gene cluster of $P$. stutzeri Choll and a respective HIP intermediate with a shortened CoA-activated carboxylic $C_{1}$ side chain has been identified [84].

Further degradation of these compounds has been primarily studied in Mycobacterium and Rhodococcus strains [125] as well as C. testosteroni TA441 [39,128-130]. Briefly, a double bond is introduced into former ring $\mathrm{C}$ and former ring $\mathrm{D}$ is hydrolytically cleaved by an enoyl-CoA hydratase. Subsequently, ring $\mathrm{C}$ is opened and the resulting linear bicarboxylic acid is cleaved into propionyl-CoA and succinyl-CoA. Homologs of all key enzymes involved in this degradation are also present in other bile acid-degrading bacteria (Table 1).

\subsection{Fate of Hydroxy Groups on the Steroid Nucleus}

The number, position, and conformation of hydroxy substituents on the steroid nucleus play a crucial role in the bacterial degradation of bile acids. Although R. jostii RHA1 can grow with cholic acid, it is not capable of metabolizing other bile acids such as chenodeoxycholic acid or deoxycholic acid [28]. P. stutzeri Chol1 grows with cholic, chenodeoxycholic, deoxycholic, and lithocholic acid but it cannot degrade the steroid skeleton of ursodeoxycholic acid $(\mathrm{V})$ which is the $7 \beta$-epimer of chenodeoxycholic acid $[40,84]$ (Figure 2). Accordingly, degradation of different bile acids requires adaptational reaction steps, depending on the bile acid hydroxylation pattern.

\subsubsection{Fate of the $12 \alpha$-Hydroxy Group}

During degradation of $12 \alpha$-hydroxy bile acids, the $12 \alpha$-hydroxy group is isomerized to the $\beta$-conformation in P. stutzeri Chol1 and $C$. testosteroni TA441 via consecutive oxidation and reduction reactions (Figure 7) [19,37]. In C. testosteroni, this inversion is catalyzed by the dehydrogenases SteA and SteB and has been proposed to be indispensable for the following $9 \alpha$-hydroxylation step opening the B-ring [37]. In P. stutzeri Chol1, the $12 \alpha$-hydroxy group of $12 \alpha$-DHADD (XII) is oxidized with $\mathrm{NAD}^{+}$and the resulting 12-keto intermediate is subsequently reduced to $12 \beta$-DHADD (VII) with NADPH as electron donor [33]. After removal of the A-ring, the former $12 \beta$-hydroxy group is removed by a two-step reductive dehydroxylation catalyzed by a dehydratase (Hsh1) and an oxidoreductase (Sor1) in strain Chol1 (Figure 6) [84]. Homologs of steA, steB, sor1, and hsh1 are found in the steroid degradation gene clusters of C. testosteroni, Sphingobium sp. strain Chol11 and Azoarcus sp. strain Aa7 in distinct sub-clusters with similar gene syntenies [23,84], suggesting that the isomerization and subsequent reductive dehydroxylation of the $12 \alpha$-hydroxy group are characteristic features in bile acid-degrading Proteobacteria. The formation of a HIP derivative without a hydroxy group at former C12 during cholic acid degradation [43] suggests that this hydroxy group is also removed prior to HIP degradation in $R$. jostii RHA1, which was hypothesized to be catalyzed by a putative enoyl-CoA hydratase [125]. 


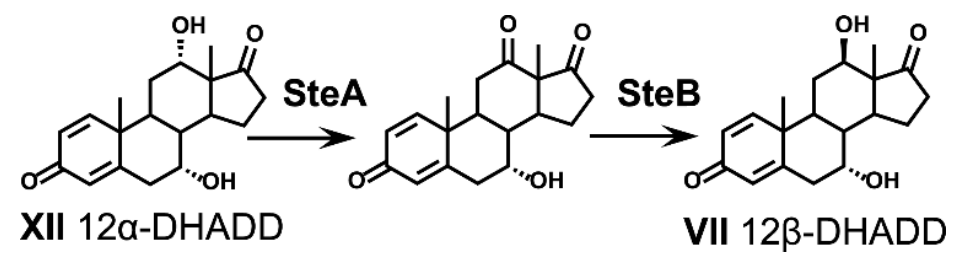

Figure 7. Stereoconversion of the 12-hydroxy group during bile acid degradation. Enzymes were identified in C. testosteroni TA441. For bile acids, the respective deprotonated bile salts are depicted.

\subsubsection{Fate of the $7 \alpha$-Hydroxy Group}

Transformation or degradation reactions of the $7 \alpha$-hydroxy group of cholic and chenodeoxycholic acid differ widely among bile acid-degrading bacteria. In P. stutzeri Chol1, and presumably $R$. jostii RHA1, the $7 \alpha$-hydroxy group is maintained up to the level of HIP degradation [43,84]. During HIP degradation, a hydroxy group in $\beta$-position is required for the removal of the carboxylic $C_{3}$ side chain (see above, Figure 6). P. stutzeri Chol1 mutant strains lacking the genes encoding the HIP-CoA ACAD system, which introduces a double bond into the HIP side chain prior to hydroxylation, showed no phenotype growing with the $7 \alpha$-hydroxy bile acids cholic and chenodeoxycholic acid compared to the wildtype [84]. In contrast, these mutants accumulated a HIP derivative from deoxycholic and lithocholic acid. This suggested that dehydrogenation and hydration of the HIP side chain are not required during degradation of $7 \alpha$-hydroxy bile acids in this strain and that the degradation pathways of cholic, deoxycholic, chenodeoxycholic, and lithocholic acid converge at a central HIP-derivative carrying a hydroxy group in the $C_{3}$ side chain [84].

In contrast, recent studies have suggested that the $7 \alpha$-hydroxy group of cholic acid is removed at the stage of HIP degradation in C. testosteroni TA441. Gene deletion mutants lacking the $s c d D$ (enoyl-CoA hydratase), $s c d E$ (enoyl-CoA hydratase), and $s c d F$ (3-ketoacylCoA transferase) genes, which were shown to be involved in the removal of the $\mathrm{C}_{3} \mathrm{HIP}$ side chain, accumulated a HIP derivative with a double bond in the $C_{3}$ side chain from different steroid substrates, including $7 \alpha$-hydroxy bile acids [36,39]. The authors speculated that the $7 \alpha$-hydroxy-group is removed by dehydration after CoA-activation of the HIP side chain and that subsequent hydration of the resulting double bond might result in a stereo-inversion of the hydroxy group.

2.9.3. Dehydratation of 7-Hydroxy Groups during Bile Acid Degradation via $\Delta^{4,6}$-3-Keto Intermediates

The $\alpha$-Proteobacteria Sphingobium sp. strain Chol11, Sphingobium herbicidovorans MH, Novosphingobium aromaticivorans F199, and C. tardaugens NBRC16725 initiate the degradation of cholic acid and other 7-hydroxy bile acids via an alternative route, which had been designated the $\Delta^{4,6}$-variant $[23,40]$ (Figure 8). Additionally, the Actinobacterium Dietzia sp. strain Chol2 uses this variant [18]. In these organisms, the 7-hydroxy group is removed from the intact bile acid molecule after partial oxidation of the A-ring via an enzymatic dehydration reaction, leading to the formation of a double bond between C6 and $C 7\left(\Delta^{6}\right)$. In Sphingobium sp. strain Chol11, dehydration of the $7 \alpha$-hydroxy group is catalyzed by the hydroxysteroid dehydratase Hsh2 with 3-keto- $\Delta^{4}$ intermediates as physiological substrates [40], yielding intermediates with a 3-keto- $\Delta^{4,6}$-diene structure, such as 12-hydroxy-3-oxo-4,6-choldienoic acid (HOCDA, XIV). As mentioned above, this reaction is required by Azoarcus sp. strain Aa7 to be able to degrade $7 \alpha$-hydroxy bile acids via the anaerobic 2,3-seco pathway [25]. In contrast, Hsh2 is not essential for the growth of Sphingobium sp. strain Chol11 with cholic acid or chenodeoxycholic acid but is necessary for maximum growth efficiency with these $7 \alpha$-hydroxysteroids. The resulting $\Delta^{6}$-double bond is not reduced or rehydrated prior to $9 \alpha$-hydroxylation and subsequent degradation of the bile acid nucleus $[18,40]$. Sphingobium sp. strain Chol11 harbors at least one more hydroxysteroid dehydratase specific for the $7 \beta$-hydroxy group of ursodeoxycholic acid [40]. In supernatants of cholic acid-grown cultures of this strain, $12 \beta$-hydroxy-androsta-1,4,6-triene-3,17-dione 
(HATD, XVI) occurs as a degradation intermediate [18]. This ADD-derivative with an additional $\Delta^{6}$-double bond indicates that side-chain degradation is the next metabolic step in the degradation of 3-keto- $\Delta^{4,6}$-diene intermediates. The first results indicate that the further degradation of HATD proceeds via a 9,10-seco-steroid [23,78] (preprint). The $\Delta^{4,6}$ degradation pathway variant for $7 \alpha$-hydroxy bile acids is currently under investigation with a special focus on the above-mentioned differences in side-chain degradation.

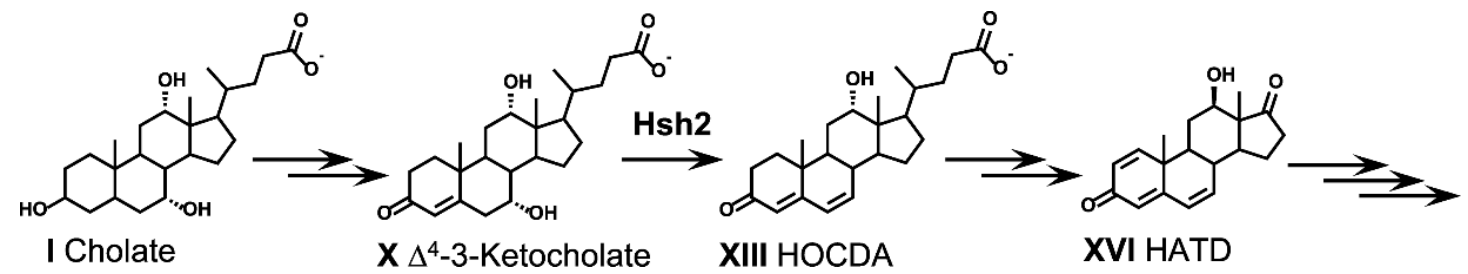

Figure 8. Degradation of bile acids via the $\Delta^{4,6}$-variant of the 9,10-seco pathway as found, e.g., in Sphingobium sp. strain Chol11. For bile acids, the respective deprotonated bile salts are depicted. Abbreviations: HATD, $12 \beta$-Hydroxy-androsta1,4,6-triene-3,17-dione.

\section{Resistance Mechanisms against the Toxic Effects of Bile Acids}

Bile acids and their derivatives are highly toxic compounds for bacterial cells. Due to their amphiphilic character, bile acids lead to an increase in membrane permeability and may cause cell lysis [131,132]. In the bacterial cytoplasm, bile acids can cause DNA damage, protein-unfolding, and disulfide stress $[133,134]$.

In the small intestine, bile acids have been shown to possess an important controlling effect for the bacterial population due to their antimicrobial properties [9]. Intestinal bacteria, facing up to $20 \mathrm{mM}$ bile-acid concentrations in the duodenum [54], have evolved multiple resistance mechanisms against the toxic effects of bile acids [132,135]: The outer membrane of Gram-negative bacteria acts as a diffusion barrier and constitutes the first protection against bile acid toxicity $[136,137]$. Additionally, many intestinal bacteria have energy-dependent efflux systems constituting effective protection by means of avoiding the accumulation of bile acids in the cytoplasm [54,132,135,138].

Similarly, bacteria using bile acids as growth substrates must actively protect themselves against the toxic effects of bile acids. However, for metabolism and energy conservation, these carbon- and energy-rich but lethal compounds must be taken up into the cytoplasm. Moreover, degradation intermediates such as ADD and 9,10-seco metabolites can exhibit additional toxicity in the cell $[19,139,140]$. Thus, bile acid-degrading bacteria must possess precisely regulated protection mechanisms, which keep the intracellular concentration of toxic bile acids and their degradation intermediates below a critical level, while providing sufficient intracellular bile acid substrate concentrations for metabolism and energy conservation. Presumably, part of the energy generated during bile acid metabolism must be invested into protection mechanisms.

To that effect, degradation itself poses an effective detoxification mechanism. Especially the first A-ring oxidation steps presumably produce less toxic compounds as the removal of one hydroxy group from the hydrophilic side of the molecule probably decreases the detergent character. As a protection mechanism, degradation should be fast and tightly regulated to prevent overflow at any phase. Interestingly, the $5 \beta-\Delta^{4}-\mathrm{KSTD}$ from Sphingobium sp. strain Chol11 involved in A-ring oxidation is a very fast enzyme that showed strong substrate inhibition [42]. This results in a fast transformation of 3-keto bile acids to their less toxic $\Delta^{4}$ derivatives, while an overflow of the subsequent pathway including slower enzymes $[40,41]$ is prevented.

Additionally, it has been speculated that efflux-pump-mediated excretion of bile acids and some degradation intermediates might contribute to the control of the intracellular concentration [31,43]. The susceptibility of P. stutzeri Chol1 to cholic acid increases in the presence of the uncoupling agent carbonyl cyanide $m$-chlorophenylhydrazone (CCCP), indicating that an intact proton-motive-force contributes to the protection against bile 
acids [19]. These findings support the hypothesis that the efflux of bile acids is a crucial defense mechanism in bile acid-degrading bacteria. The steroid degradation gene cluster of $P$. stutzeri Choll contains a gene encoding a Resistance-Nodulation-Division type (RND) transporter, which is a candidate for such an efflux system. In $R$. jostii RHA1 two transporters belonging to the ATP-binding cassette (ABC) family and major facilitator superfamily (MFS) are essential for the re-uptake of transiently excreted and potentially toxic cholic-acid degradation intermediates [43]. Further research is required to substantiate the role of exporters in bile-acid metabolism.

\section{Regulation of Bile-Acid Degradation}

The structural complexity and the molecular size of bile acids require more than thirty biochemical steps for their complete degradation to $\mathrm{CO}_{2}$, suggesting that bile acid degradation has to be tightly regulated. In addition, adaptation to bile acid toxicity presumably requires further regulatory mechanisms controlling the uptake and export of substrates and degradation intermediates. In P. stutzeri Chol1 [26], Sphingobium sp. strain Chol11 [23], and Dietzia sp. strain Chol2 (unpublished data), complete cholic acid degradation is not induced in cells grown with non-steroidal substrates, indicating regulatory mechanisms for bile-acid degradation in these strains. However, the knowledge about the regulation of bile acid metabolism is limited. For Sphingobium sp. strain Chol11, proteome analyses clearly showed that enzymes encoded in several gene clusters were significantly more abundant when the strain was grown with bile acids, indicating regulation of these clusters in response to the presence of bile acids [23].

In C. testosteroni, TeiR and HsdR are positive regulators of steroid metabolism [141,142]. TeiR localizes at one of the cell poles, enabling steroid sensing and motility towards steroid substrates. The binding of testosterone and some other steroids to TeiR activates a kinase-dependent signaling mechanism. The LysR-type transcriptional regulator HsdR activates the transcription of $h s d A$ encoding a $3 \alpha$-hydroxysteroid-dehydrogenase [142]. Two genes encoding putative TeiR-like transcriptional regulators are also found in the steroid degradation gene cluster of P. stutzeri Chol1. Deletion of one of these genes (C211_RS11295) led to a strong delay of the onset of cholic acid degradation and growth, indicating a regulatory function of the respective protein during bile acid degradation (unpublished data). However, distinct regulatory mechanisms are still largely unknown for bile aciddegrading Proteobacteria.

In $R$. jostii RHA1, the expression of cholic acid degradation genes is upregulated when growing with cholic acid, but not in the presence of cholesterol or pyruvate $[28,90]$. This indicates that distinct regulatory mechanisms control the expression of the different steroiddegradation gene clusters in this strain. In R. jostii RHA1 and other steroid-degrading Actinobacteria, the TetR-type transcriptional repressors KstR1 and KstR2 have been shown to control sterol metabolism [143]. KstR1 regulates the sterol side-chain and A/B ring degradation, which are induced by the cholesterol-degradation intermediate 3-oxo-4cholestenoic acid [144]. KstR2 regulates HIP degradation and KstR2 repression is relieved by HIP-CoA-esters and a lactone derivative of HIP [144,145]. Homologs of KstR1 and KstR2 are not present in bile acid-degrading Proteobacteria, but a KstR homolog is encoded in the cholic-acid degradation gene cluster of $R$. jostii RHA1.

\section{Potential Ecological Effects of Bacterial Bile-Acid Degradation}

Besides their function as detergents in digestion, bile acids act as regulatory compounds $[3,146,147]$ and also signaling compounds between different organisms, e.g., in aquatic vertebrates $[15,16]$. As such, distinctive bile acids and bile alcohols function as migratory hormones in aquatic vertebrates such as sea lampreys [15,148-151]. The bile acid $5 \alpha$-cyprinol sulfate that is excreted by fish induces a predator avoidance behavior in Daphnia called diel vertical migration and thus acts as a chemical cue for Daphnia to sense the presence of predators [152]. Additionally, it was recently reported that bile acids are 
natural ligands of the mouse accessory olfactory system [153] indicating that they may also have a signaling function among terrestrial vertebrates.

Therefore, bacterial bile acid degradation in these habitats may interfere with those signaling systems via the removal or transformation of signaling compounds. The degradation of these signal compounds could also be very important, e.g., in the case of Daphnia where bile acids indicate the presence of predators, a system that only works if bile acids are removed again. Furthermore, interference of bile acid degradation intermediates with signaling pathways might be possible, especially as bile acids and alcohols with a 3-keto$\Delta^{4,6}$ structure similar to HOCDA (XIV) are pheromones of the sea lamprey Petromyzon marinus [149,154].

Besides possible effects on vertebrates, bile acid degradation might also have an impact on invertebrates such as the soil nematode Caenorhabditis elegans $[155,156]$. C. elegans possesses at least 284 genes for nuclear hormone receptors (NHR), which bind steroid hormones and other ligands, in contrast to only 48 genes coding for NHR in humans [157]. Dafachronic acids, which are similar to bile acids, are important NHR-binding steroid hormones in C. elegans, regulating development $[158,159]$. Bacterial degradation or transformation of dafachronic acids could interfere with this mechanism.

Steroid intermediates such as ADDs accumulate transiently in the extracellular environment during bacterial degradation of bile acids under laboratory conditions $[18,19,31,43]$ and during degradation of chenodeoxycholic acid in soil samples [12]. In analogy, bacterial bile acid transformation products may also occur in aquatic and terrestrial environments with a high input of bile acids such as manured agricultural soils, making them available to other bacteria and eukaryotic organisms. A transient accumulation of ADDs has been shown [160] and calculated in models [161] for $\mathrm{C}_{19}$ steroids that are produced during the microbial degradation of sterol compounds from manure fertilizer.

Thus, these compounds may have ecological effects as some of the degradation intermediates are very similar to steroid hormones. For example, the bacterial degradation of lithocholic acid produces ADD [84], which has androgenic effects on mammals, similar to testosterone [162,163]. In addition, differently hydroxylated ADDs and ADs are exported as prominent intermediates during the degradation of other bile acids $[18,19,31,66]$. Although only little information is available regarding the endocrine effects of hydroxylated ADDs and ADs, they might also have androgenic potential, since exogenous steroids with similar structures to testosterone affect the androgen signaling pathways in vertebrates $[164,165]$. Similarly, endocrine effects of bacterial sterol degradation on fish were suggested: masculinization of fish populations in rivers receiving paper-mill effluents [166-168] was traced back to the bacterial transformation of plant-derived sterols into androgenic steroids [169-171].

During the degradation of chenodeoxycholic acid (II), $7 \alpha-\mathrm{OH}$ ADD is produced, which was shown to have adverse effects on the nematode Caenorhabditis elegans [12]. $7 \alpha-\mathrm{OH}$ ADD decreased the reproduction and development and induced behavioral changes of $C$. elegans when added to the medium. A deletion mutant lacking the putative testosterone receptor NHR-69 did not display this phenotype, suggesting that $7 \alpha-\mathrm{OH}$ ADD effects in C. elegans are mediated via this receptor NHR-69. Thus, the remarkably high number of NHR in C. elegans could be important for environmental signaling via steroid compounds potentially including bacterial bile-acid degradation intermediates [172-174].

However, for assessing potential endocrine effects of steroids originating from bacterial bile acid degradation on soil and water fauna, especially in areas with a high input of manure, further studies are necessary.

The transient extracellular accumulation of steroid degradation intermediates could also lead to cross-feeding processes between bile acid-degrading bacteria in soil and water. Given the abundance of bile acid-degrading bacteria, these bacteria might not only compete for these energy-rich substrates but also for their degradation intermediates. Cross feeding has been studied with P. stutzeri Chol1 and Sphingobium sp. strain Chol11. While P. stutzeri Chol1 degrades $7 \alpha$-hydroxy bile acids, such as cholic acid and chenodeoxycholic acid, via intermediates with a 3-keto- $\Delta^{1,4}$ structure of the steroid (e.g., VI), Sphingobium sp. 
strain Chol11 degrades these compounds via intermediates with a 3-keto- $\Delta^{4,6}$ structure (XIV) $[18,40]$. However, the latter strain is also able to use steroids with a 3-keto- $\Delta^{1,4}$ structure for growth. In contrast to that, $P$. stutzeri cannot grow with $\Delta^{4,6}-3$-keto compounds formed by Sphingobium sp. strain Chol11 and transforms them into dead-end metabolites that accumulate in the culture supernatant. Apparently, Sphingobium sp. strain Chol11 has a broader metabolic repertoire for the utilization of bile acids, which could be a selective advantage in competing for these substrates in natural habitats [40]. Additionally, the conversion of bile acids into steroids, which are not bioavailable to competitors, could also serve as a strategy of excluding competition. The fact that cross-feeding processes could occur as well as the observation that such cross-feeding may create novel steroid compounds with potential endocrine effects reveals the complexity and the impact that bacterial bile-acid degradation might have in natural habitats.

\section{Applied Aspects of Bacterial Bile-Acid Degradation}

Plant-based phytosterols such as stigmasterol, campesterol, and diosgenin are the major raw materials for the steroid industry today [175]. These starting materials are microbially transformed into a few key products, e.g., ADD and 20-carboxy-pregna-4-en3-one, which are subsequently modified to high-value drugs such as contraceptives and corticosteroids. However, biotechnological processes are also required for the production of bile acid-derived drugs [176]. Ursodeoxycholic acid (V) inhibits the proliferation of colon cancer cells and is used as an agent for the treatment of primary sclerosing cholangitis and for the dissolution of gallstones [177-179]. The chemical synthesis of ursodeoxycholic acid from cholic acid is accomplished by seven chemical reactions with a yield of about $30 \%$. Using a bacterial whole-cell biotransformation process combined with these chemical steps has been reported to increase the yield to $95 \%$ [180].

Probiotic bacteria could be used to increase bacterial bile-acid deconjugation in the gut, which would decrease the re-absorption of bile acids in the enterohepatic cycle and consequently increase bile-acid production from cholesterol leading to higher cholesterol consumption in the body [181-183].

\section{Conclusions and Future Perspectives}

The bacterial degradation of bile acids has numerous relevant aspects for fundamental and applied research. Thirty-nine years after the seminal review by Hayakawa about bacterial bile acid degradation [48] the genes and enzymes for many of the postulated metabolic pathways have been characterized. In addition, novel and unexpected reactions for the breakdown of bile acids have been discovered indicating alternative pathways, which are currently being analyzed. Here, the elucidation of side-chain degradation by the Sphingomonadaceae is a key aspect. The understanding of the metabolic pathways for bile acid degradation is the prerequisite for addressing the potential ecological effects of the hormone-like metabolites that arise as intermediates during the breakdown of bile acids in soil and water. As these metabolic pathways comprise numerous reaction steps and as the parent molecules, as well as some degradation metabolites, have toxic effects, bile acid degradation is a physiological challenge for bacteria that will require complex regulatory networks. Finally, the ongoing discovery of novel physiological functions of bile acids in vertebrates [2] indicates that the targeted biotechnological production of novel bile acid-derivatives with engineered bacterial strains might have pharmacological potential.

Author Contributions: All authors were equally involved in preparation of this manuscript. All authors have read and agreed to the published version of the manuscript.

Funding: Research on the bacterial degradation of bile acids in our laboratory is funded by grants of the Deutsche Forschungsgemeinschaft (DFG) to BP (projects PH71/3-1 and 3-2, INST 211/646-1 FUGG).

Institutional Review Board Statement: Not applicable.

Informed Consent Statement: Not applicable. 
Acknowledgments: The authors would like to thank the following former and current co-workers and cooperation partners for their contributions to research on bile acid degradation in our laboratory at the Universities of Münster (Karin Niermann, Kirsten Heuer, Kevin Ludwig, Rebekka Lülf, Phil Richtsmeier, Maximilian Wege, Lea Elsner, Sebastian Borgert, Gina Marke, Almuth Mährlein), Konstanz (Henrike Seidinger née Erdbrink, Antoinette Birkenmaier, Vemparthan Suvekbala) and Potsdam (Heiko Möller).

Conflicts of Interest: The authors declare no conflict of interest.

\section{References}

1. Hofmann, A.F.; Hagey, L.R.; Krasowski, M.D. Bile salts of vertebrates: Structural variation and possible evolutionary significance. J. Lipid Res. 2010, 51, 226-246. [CrossRef]

2. Vítek, L.; Haluzík, M. The role of bile acids in metabolic regulation. J. Endocrinol. 2016, 228, R85-R96. [CrossRef]

3. Hylemon, P.B.; Zhou, H.; Pandak, W.M.; Ren, S.; Gil, G.; Dent, P. Bile acids as regulatory molecules. J. Lipid Res. 2009, 50, 1509-1520. [CrossRef]

4. Ridlon, J.M.; Kang, D.-J.J.; Hylemon, P.B. Bile salt biotransformations by human intestinal bacteria. J. Lipid Res. 2006, 47, 241-259. [CrossRef]

5. Funabashi, M.; Grove, T.L.; Wang, M.; Varma, Y.; McFadden, M.E.; Brown, L.C.; Guo, C.; Higginbottom, S.; Almo, S.C.; Fischbach, M.A. A metabolic pathway for bile acid dehydroxylation by the gut microbiome. Nature 2020, 582, 566-570. [CrossRef]

6. Ridlon, J.M. Conceptualizing the vertebrate sterolbiome. Appl. Environ. Microbiol. 2020, 86, 1-22. [CrossRef]

7. Doden, H.L.; Ridlon, J.M. Microbial hydroxysteroid dehydrogenases: From alpha to omega. Microorganisms 2021, 9, 469. [CrossRef]

8. Winston, J.A.; Theriot, C.M. Diversification of host bile acids by members of the gut microbiota. Gut Microbes 2020, 11, 158-171. [CrossRef]

9. Ridlon, J.; Kang, D.; Hylemon, P.; Bajaj, J. Bile acids and the gut microbiome. Curr. Opin. Gastroenterol. 2014, 30, 332-338. [CrossRef]

10. Kriaa, A.; Bourgin, M.; Potiron, A.; Mkaouar, H.; Jablaoui, A.; Gérard, P.; Maguin, E.; Rhimi, M. Microbial impact on cholesterol and bile acid metabolism: Current status and future prospects. J. Lipid Res. 2019, 60, 323-332. [CrossRef]

11. Tyagi, P.; Edwards, D.R.; Coyne, M.S. Use of sterol and bile acid biomarkers to identify domesticated animal sources of fecal pollution. Water. Air. Soil Pollut. 2008, 187, 263-274. [CrossRef]

12. Mendelski, M.N.; Dölling, R.; Feller, F.M.; Hoffmann, D.; Ramos Fangmeier, L.; Ludwig, K.C.; Yücel, O.; Mährlein, A.; Paul, R.J.; Philipp, B. Steroids originating from bacterial bile acid degradation affect Caenorhabditis elegans and indicate potential risks for the fauna of manured soils. Sci. Rep. 2019, 9, 11120. [CrossRef] [PubMed]

13. Tyagi, P.; Edwards, D.R.; Coyne, M.S. Fecal sterol and bile acid biomarkers: Runoff concentrations in animal waste-amended pastures. Water. Air. Soil Pollut. 2009, 198, 45. [CrossRef]

14. Elhmmali, M.M.; Roberts, D.J.; Evershed, R.P. Combined analysis of bile acids and sterols/stanols from riverine particulates to assess sewage discharges and other fecal sources. Environ. Sci. Technol. 2000, 34, 39-46. [CrossRef]

15. Buchinger, T.J.; Li, W.; Johnson, N.S. Bile salts as semiochemicals in fish. Chem. Senses 2014, 39, 647-654. [CrossRef]

16. Meredith, T.L.; Caprio, J.; Kajiura, S.M. Sensitivity and specificity of the olfactory epithelia of two elasmobranch species to bile salts. J. Exp. Biol. 2012, 215, 2660-2667. [CrossRef]

17. Merino, E.; Barrientos, A.; Rodríguez, J.; Naharro, G.; Luengo, J.M.; Olivera, E.R. Isolation of cholesterol- and deoxycholatedegrading bacteria from soil samples: Evidence of a common pathway. Appl. Microbiol. Biotechnol. 2013, 97, 891-904. [CrossRef]

18. Holert, J.; Yücel, O.; Suvekbala, V.; Kulić, Ž.; Möller, H.; Philipp, B. Evidence of distinct pathways for bacterial degradation of the steroid compound cholate suggests the potential for metabolic interactions by interspecies cross-feeding. Environ. Microbiol. 2014, 16, 1424-1440. [CrossRef]

19. Philipp, B.; Erdbrink, H.; Suter, M.J.F.; Schink, B. Degradation of and sensitivity to cholate in Pseudomonas sp. strain Chol1. Arch. Microbiol. 2006, 185, 192-201. [CrossRef] [PubMed]

20. Holert, J.; Cardenas, E.; Bergstrand, L.H.; Zaikova, E.; Hahn, A.S.; Hallam, S.J.; Mohn, W.W. Metagenomes reveal global distribution of bacterial steroid catabolism in natural, engineered, and host environments. mBio 2018, 9, e02345-17. [CrossRef] [PubMed]

21. Lengeler, J.; Drews, G.; Schlegel, H. Biology of the Prokaryotes; Lengeler, J.W., Drews, G., Schlegel, H.G., Eds.; Thieme: Stuttgart, Germany, 2009; ISBN 9781444313307.

22. Bull, I.D.; Lockheart, M.J.; Elhmmali, M.M.; Roberts, D.J.; Evershed, R.P. The origin of faeces by means of biomarker detection. Environ. Int. 2002, 27, 647-654. [CrossRef]

23. Feller, F.M.; Wöhlbrand, L.; Holert, J.; Schnaars, V.; Mohn, W.W.; Rabus, R.; Philipp, B. Proteome, bioinformatic and functional analyses reveal a distinct and conserved metabolic pathway for bile salt degradation in the Sphingomonadaceae. Appl. Environ. Microbiol. 2021. [CrossRef] [PubMed]

24. Horinouchi, M.; Hayashi, T.; Kudo, T. Steroid degradation in Comamonas testosteroni. J. Steroid Biochem. Mol. Biol. 2012, 129, 4-14. [CrossRef] [PubMed] 
25. Yücel, O.; Borgert, S.R.; Poehlein, A.; Niermann, K.; Philipp, B. The $7 \alpha$-hydroxysteroid dehydratase Hsh2 is essential for anaerobic degradation of the steroid skeleton of $7 \alpha$-hydroxyl bile salts in the novel denitrifying bacterium Azoarcus sp. strain Aa7. Environ. Microbiol. 2019, 21, 800-813. [CrossRef]

26. Birkenmaier, A.; Holert, J.; Erdbrink, H.; Möller, H.M.; Friemel, A.; Schönenberger, R.; Suter, M.J.F.; Klebensberger, J.; Philipp, B. Biochemical and genetic investigation of initial reactions in aerobic degradation of the bile acid cholate in Pseudomonas sp. strain Chol1. J. Bacteriol. 2007, 189, 7165-7173. [CrossRef] [PubMed]

27. Bergstrand, L.H.; Cardenas, E.; Holert, J.; van Hamme, J.D.; Mohn, W.W. Delineation of steroid-degrading microorganisms through comparative genomic analysis. mBio 2016, 7, 1-14. [CrossRef]

28. Mohn, W.W.; Wilbrink, M.H.; Casabon, I.; Stewart, G.R.; Liu, J.; van der Geize, R.; Eltis, L.D. Gene cluster encoding cholate catabolism in Rhodococcus spp. J. Bacteriol. 2012, 194, 6712-6719. [CrossRef]

29. Guevara, G.; de las Heras, L.F.; Perera, J.; Llorens, J.M.N. Functional characterization of 3-ketosteroid 9 $\alpha$-hydroxylases in Rhodococcus ruber strain chol-4. J. Steroid Biochem. Mol. Biol. 2017, 172, 176-187. [CrossRef]

30. Shtratnikova, V.Y.; Schelkunov, M.I.; Fokina, V.V.; Bragin, E.Y.; Lobastova, T.G.; Shutov, A.A.; Kazantsev, A.V.; Donova, M. V Genome-wide transcriptome profiling provides insight on cholesterol and lithocholate degradation mechanisms in Nocardioides simplex VKM Ac-2033D. Genes 2020, 11, 1229. [CrossRef]

31. Philipp, B. Bacterial degradation of bile salts. Appl. Microbiol. Biotechnol. 2011, 89, 903-915. [CrossRef]

32. Olivera, E.R.; Luengo, J.M. Steroids as environmental compounds recalcitrant to degradation: Genetic mechanisms of bacterial biodegradation pathways. Genes 2019, 10, 512. [CrossRef]

33. Holert, J.; Kulić, Ž.; Yücel, O.; Suvekbala, V.; Suter, M.J.F.; Möller, H.M.; Philipp, B. Degradation of the acyl side chain of the steroid compound cholate in Pseudomonas sp. strain Chol1 proceeds via an aldehyde intermediate. J. Bacteriol. 2013, 195, 585-595. [CrossRef]

34. Holert, J.; Jagmann, N.; Philipp, B. The essential function of genes for a hydratase and an aldehyde dehydrogenase for growth of Pseudomonas sp. strain Chol1 with the steroid compound cholate indicates an aldolytic reaction step for deacetylation of the side chain. J. Bacteriol. 2013, 195, 3371-3380. [CrossRef]

35. Barrientos, Á.; Merino, E.; Casabon, I.; Rodríguez, J.; Crowe, A.M.; Holert, J.; Philipp, B.; Eltis, L.D.; Olivera, E.R.; Luengo, J.M. Functional analyses of three acyl-CoA synthetases involved in bile acid degradation in Pseudomonas putida DOC21. Environ. Microbiol. 2015, 17, 47-63. [CrossRef] [PubMed]

36. Horinouchi, M.; Hayashi, T.; Koshino, H.; Malon, M.; Hirota, H.; Kudo, T. Identification of 9 $\alpha$-hydroxy-17-oxo-1,2,3,4,10,19hexanorandrost-6- en-5-oic acid and $\beta$-oxidation products of the C-17 side chain in cholic acid degradation by Comamonas testosteroni TA441. J. Steroid Biochem. Mol. Biol. 2014, 143, 306-322. [CrossRef] [PubMed]

37. Horinouchi, M.; Hayashi, T.; Koshino, H.; Malon, M.; Yamamoto, T.; Kudo, T. Identification of genes involved in inversion of stereochemistry of a C-12 hydroxyl group in the catabolism of cholic acid by Comamonas testosteroni TA441. J. Bacteriol. 2008, 190, 5545-5554. [CrossRef] [PubMed]

38. Horinouchi, M.; Hayashi, T.; Koshino, H.; Kudo, T. ORF18-disrupted mutant of Comamonas testosteroni TA441 accumulates significant amounts of 9,17-dioxo-1,2,3,4,10,19-hexanorandrostan-5-oic acid and its derivatives after incubation with steroids. J. Steroid Biochem. Mol. Biol. 2006, 101, 78-84. [CrossRef] [PubMed]

39. Horinouchi, M.; Koshino, H.; Malon, M.; Hirota, H.; Hayashi, T. Steroid degradation in Comamonas testosteroni TA441: Identification of the entire $\beta$-oxidation cycle of the cleaved B ring. Appl. Environ. Microbiol. 2019, 85, 1-17. [CrossRef] [PubMed]

40. Yücel, O.; Drees, S.; Jagmann, N.; Patschkowski, T.; Philipp, B. An unexplored pathway for degradation of cholate requires a $7 \alpha$-hydroxysteroid dehydratase and contributes to a broad metabolic repertoire for the utilization of bile salts in Novosphingobium sp. strain Chol11. Environ. Microbiol. 2016, 18, 5187-5203. [CrossRef] [PubMed]

41. Yücel, O.; Holert, J.; Ludwig, K.C.; Thierbach, S.; Philipp, B. A novel steroidcoenzyme A ligase from Novosphingobium sp. strain Chol11 is essential for an alternative degradation pathway for bile salts. Appl. Environ. Microbiol. 2018, 84, 1-16. [CrossRef]

42. Feller, F.M.; Marke, G.; Drees, S.L.; Wöhlbrand, L.; Rabus, R.; Philipp, B. Substrate inhibition of 5 $\beta$ - $\Delta^{4}$-3-ketosteroid dehydrogenase in Sphingobium sp. strain Chol11 acts as circuit breaker during growth with toxic bile salts. Front. Microbiol. 2021, 1, 655312 [CrossRef]

43. Swain, K.; Casabon, I.; Eltis, L.D.; Mohn, W.W. Two transporters essential for reassimilation of novel cholate metabolites by Rhodococcus jostii RHA1. J. Bacteriol. 2012, 194, 6720-6727. [CrossRef]

44. Wipperman, M.F.; Sampson, N.S.; Thomas, S.T.; Thomas, S.T. Pathogen roid rage: Cholesterol utilization by Mycobacterium tuberculosis. Crit. Rev. Biochem. Mol. Biol. 2014, 49, 269-293. [CrossRef] [PubMed]

45. Galán, B.; García-Fernández, J.; Felpeto-Santero, C.; Fernández-Cabezón, L.; García, J.L. Bacterial metabolism of steroids. In Aerobic Utilization of Hydrocarbons, Oils and Lipids; Rojo, F., Ed.; Springer International Publishing: Cham, Switzerland, 2017; pp. 1-22. ISBN 978-3-319-39782-5.

46. Petrusma, M.; Van Der Geize, R.; Dijkhuizen, L. 3-Ketosteroid $9 \alpha$-hydroxylase enzymes: Rieske non-heme monooxygenases essential for bacterial steroid degradation. Antonie Leeuwenhoek 2014, 106, 157-172. [CrossRef]

47. Dresen, C.; Lin, L.Y.C.; D'Angelo, I.; Tocheva, E.I.; Strynadka, N.; Eltis, L.D. A flavin-dependent monooxygenase from Mycobacterium tuberculosis involved in cholesterol catabolism. J. Biol. Chem. 2010, 285, 22264-22275. [CrossRef] [PubMed]

48. Hayakawa, S. Microbial transformation of bile acids. A unified scheme for bile acid degradation, and hydroxylation of bile acids. Z. Allg. Mikrobiol. 1982, 22, 309-326. [CrossRef] [PubMed] 
49. Warnke, M.; Jacoby, C.; Jung, T.; Agne, M.; Mergelsberg, M.; Starke, R.; Jehmlich, N.; von Bergen, M.; Richnow, H.-H.; Brüls, T.; et al. A patchwork pathway for oxygenase-independent degradation of side chain containing steroids. Environ. Microbiol. 2017, 19, 4684-4699. [CrossRef] [PubMed]

50. Wang, P.H.; Lee, T.H.; Ismail, W.; Tsai, C.Y.; Lin, C.W.; Tsai, Y.W.; Chiang, Y.R. An oxygenase-independent cholesterol catabolic pathway operates under oxic conditions. PLoS ONE 2013, 8, e66675. [CrossRef] [PubMed]

51. Holert, J.; Alam, I.; Larsen, M.; Antunes, A.; Bajic, V.B.; Stingl, U.; Philipp, B. Genome sequence of Pseudomonas sp. strain Chol1, a model organism for the degradation of bile salts and other steroid compounds. Genome Announc. 2013, 1, e00014-12. [CrossRef]

52. Horinouchi, M.; Kurita, T.; Yamamoto, T.; Hatori, E.; Hayashi, T.; Kudo, T.; Hirosawa, W.-S. Steroid degradation gene cluster of Comamonas testosteroni consisting of 18 putative genes from meta-cleavage enzyme gene tesB to regulator gene tesR. Biochem. Biophys. Res. Commun. 2004, 324, 597-604. [CrossRef]

53. Cabral, D.J.; Small, D.M.; Lilly, H.S.; Hamilton, J.A. Transbilayer movement of bile acids in model membranes. Biochemistry 1987, 26, 1801-1804. [CrossRef]

54. Thanassi, D.G.; Cheng, L.W.; Nikaido, H. Active efflux of bile salts by Escherichia coli. J. Bacteriol. 1997, 179, 2512-2518. [CrossRef]

55. Mallonee, D.H.; Hylemon, P.B. Sequencing and expression of a gene encoding a bile acid transporter from Eubacterium sp. strain VPI 12708. J. Bacteriol. 1996, 178, 7053-7058. [CrossRef]

56. Ibero, J.; Galán, B.; Rivero-Buceta, V.; García, J.L. Unraveling the $17 \beta$-estradiol degradation pathway in Novosphingobium tardaugens NBRC 16725. Front. Microbiol. 2020, 11, 588300. [CrossRef] [PubMed]

57. Somalinga, V.; Mohn, W.W. Rhodococcus jostii porin A (RjpA) functions in cholate uptake. Appl. Environ. Microbiol. 2013, 79, 6191-6193. [CrossRef] [PubMed]

58. Mohn, W.W.; Van Der Geize, R.; Stewart, G.R.; Okamoto, S.; Liu, J.; Dijkhuizen, L.; Eltis, L.D. The actinobacterial mce4 locus encodes a steroid transporter. J. Biol. Chem. 2008, 283, 35368-35374. [CrossRef]

59. Pandey, A.K.; Sassetti, C.M. Mycobacterial persistence requires the utilization of host cholesterol. Proc. Natl. Acad. Sci. USA 2008, 105, 4376-4380. [CrossRef] [PubMed]

60. Oppermann, U.C.T.; Maser, E. Characterization of a $3 \alpha$-hydroxysteroid dehydrogenase/carbonyl reductase from the Gramnegative bacterium Comamonas testosteroni. Eur. J. Biochem. 1996, 241, 744-749. [CrossRef] [PubMed]

61. Maser, E.; Xiong, G.; Grimm, C.; Ficner, R.; Reuter, K. 3 $\alpha$-hydroxysteroid dehydrogenase/carbonyl reductase from Comamonas testosteroni: Biological significance, three-dimensional structure and gene regulation. Chem. Biol. Interact. 2001, 130-132, 707-722. [CrossRef]

62. Kisiela, M.; Skarka, A.; Ebert, B.; Maser, E. Hydroxysteroid dehydrogenases (HSDs) in bacteria-A bioinformatic perspective. J. Steroid Biochem. Mol. Biol. 2012, 129, 31-46. [CrossRef] [PubMed]

63. Chen, J.; Gao, X.; Hong, L.; Ma, L.; Li, Y. Expression, purification and functional characterization of a novel $3 \alpha$-hydroxysteroid dehydrogenase from Pseudomonas aeruginosa. Protein Expr. Purif. 2015, 115, 102-108. [CrossRef]

64. Davidson, S.J.; Talalay, P. Purification and mechanism of action of a steroid $\Delta^{4}-5-\beta$-dehydrogenase. J. Biol. Chem. 1966, 241, 906-915. [CrossRef]

65. Bar-Even, A.; Noor, E.; Savir, Y.; Liebermeister, W.; Davidi, D.; Tawfik, D.S.; Milo, R. The moderately efficient enzyme: Evolutionary and physicochemical trends shaping enzyme parameters. Biochemistry 2011, 50, 4402-4410. [CrossRef] [PubMed]

66. Horinouchi, M.; Hayashi, T.; Yamamoto, T.; Kudo, T. A new bacterial steroid degradation gene cluster in Comamonas testosteroni TA441 which consists of aromatic-compound degradation genes for seco-steroids and 3-ketosteroid dehydrogenase genes. Appl. Environ. Microbiol. 2003, 69, 4421-4430. [CrossRef] [PubMed]

67. van Oosterwijk, N.; Knol, J.; Dijkhuizen, L.; Van Der Geize, R.; Dijkstra, B.W. Structure and catalytic mechanism of 3-ketosteroid$\Delta^{4}$-(5 $\left.\alpha\right)$-dehydrogenase from Rhodococcus jostii RHA1 genome. J. Biol. Chem. 2012, 287, 30975-30983. [CrossRef] [PubMed]

68. Dijkstra, B.W.; Van Oosterwijk, N.; Rohman, A. Structure and catalytic mechanism of 3-ketosteroid dehydrogenases. Procedia Chem. 2016, 18, 3-11. [CrossRef]

69. Rohman, A.; Dijkstra, B.W. Application of microbial 3-ketosteroid $\Delta^{1}$-dehydrogenases in biotechnology. Biotechnol. Adv. 2021, 49, 107751. [CrossRef]

70. Olivera, E.R.; de la Torre, M.; Barrientos, Á.; Luengo, J.M. Steroid catabolism in bacteria: Genetic and functional analyses of $s t d H$ and stdJ in Pseudomonas putida DOC21. Can. J. Biotechnol. 2018, 2, 88-99. [CrossRef]

71. Florin, C.; Kohler, T.; Grandguillot, M.; Plesiat, P. Comamonas testosteroni 3-ketosteroid- $\Delta^{4}-5 \alpha$-dehydrogenase: Gene and protein characterization. J. Bacteriol 1996, 178, 3322-3330. [CrossRef]

72. Knol, J.; Bodewits, K.; Hessels, G.I.; Dijkhuizen, L.; van der Geize, R. 3-Keto-5 $\alpha$-steroid $\Delta^{1}$-dehydrogenase from Rhodococcus erythropolis SQ1 and its orthologue in Mycobacterium tuberculosis H37Rv are highly specific enzymes that function in cholesterol catabolism. Biochem. J. 2008, 410, 339-346. [CrossRef]

73. Zhang, Q.; Ren, Y.; He, J.; Cheng, S.; Yuan, J.; Ge, F.; Li, W.; Zhang, Y.; Xie, G. Multiplicity of 3-ketosteroid $\Delta^{1}$-dehydrogenase enzymes in Gordonia neofelifaecis NRRL B-59395 with preferences for different steroids. Ann. Microbiol. 2015, 65, $1961-1971$. [CrossRef]

74. Rohman, A.; Dijkstra, B.W. The role and mechanism of microbial 3-ketosteroid $\Delta^{1}$-dehydrogenases in steroid breakdown. $J$. Steroid Biochem. Mol. Biol. 2019, 191, 105366. [CrossRef] 
75. Rohman, A.; Van Oosterwijk, N.; Thunnissen, A.M.W.H.; Dijkstra, B.W. Crystal structure and site-directed mutagenesis of 3-ketosteroid $\Delta^{1}$-dehydrogenase from Rhodococcus erythropolis SQ1 explain its catalytic mechanism. J. Biol. Chem. 2013, 288, 35559-35568. [CrossRef]

76. Itagaki, E.; Matushita, H.; Hatta, T. Steroid transhydrogenase activity of 3-ketosteroid- $\Delta^{1}$-dehydrogenase from Nocardia corallina. J. Biochem. 1990, 108, 122-127. [CrossRef] [PubMed]

77. Jerussif, R.; Ringold, H.J. The mechanism of the bacterial C-1,2 dehydrogenation of steroids. III. Kinetics and isotope effects. Biochemistry 1965, 4, 2113-2126. [CrossRef]

78. Feller, F.M.; Richtsmeier, P.; Wege, M.; Philipp, B. Comparative analysis of bile-salt degradation in Sphingobium sp. strain Chol11 and $P$. stutzeri Chol1 reveals functional diversity of $\beta$-proteobacterial steroid degradation enzymes and suggests a novel reaction sequence for side-chain degradation involving a hydroxylation step. bioRxiv 2021, 2021. [CrossRef]

79. Jones, B.V.; Begley, M.; Hill, C.; Gahan, C.G.M.; Marchesi, J.R. Functional and comparative metagenomic analysis of bile salt hydrolase activity in the human gut microbiome. Proc. Natl. Acad. Sci. USA 2008, 105, 13580-13585. [CrossRef]

80. Rösch, V.; Denger, K.; Schleheck, D.; Smits, T.H.M.; Cook, A.M. Different bacterial strategies to degrade taurocholate. Arch. Microbiol 2008, 190, 11-18. [CrossRef] [PubMed]

81. Dong, Z.; Lee, B.H. Bile salt hydrolases: Structure and function, substrate preference, and inhibitor development. Protein Sci. 2018, 27, 1742-1754. [CrossRef]

82. Casabon, I.; Crowe, A.M.; Liu, J.; Eltis, L.D. FadD3 is an acyl-CoA synthetase that initiates catabolism of cholesterol rings C and D in Actinobacteria. Mol. Microbiol. 2013, 87, 269-283. [CrossRef]

83. Warnke, M.; Jung, T.; Jacoby, C.; Agne, M.; Feller, F.M.; Philipp, B.; Seiche, W.; Breit, B.; Boll, M. Functional characterization of three specific acyl-coenzyme A synthetases involved in anaerobic cholesterol degradation in Sterolibacterium denitrificans Chol1S. Appl. Environ. Microbiol. 2018, 84, e02721-17. [CrossRef] [PubMed]

84. Holert, J.; Yücel, O.; Jagmann, N.; Prestel, A.; Möller, H.M.; Philipp, B. Identification of bypass reactions leading to the formation of one central steroid degradation intermediate in metabolism of different bile salts in Pseudomonas sp. strain Chol1. Environ. Microbiol. 2016, 18, 3373-3389. [CrossRef] [PubMed]

85. Wipperman, M.F.; Yang, M.; Thomas, S.T.; Sampson, N.S. Shrinking the fadE proteome of Mycobacterium tuberculosis: Insights into cholesterol metabolism through identification of an $\alpha_{2} \beta_{2}$ heterotetrameric acyl coenzyme A dehydrogenase family. J. Bacteriol. 2013, 195, 4331-4341. [CrossRef]

86. Yang, M.; Lu, R.; Guja, K.E.; Wipperman, M.F.; St. Clair, J.R.; Bonds, A.C.; Garcia-Diaz, M.; Sampson, N.S. Unraveling cholesterol catabolism in Mycobacterium tuberculosis: ChsE4-ChsE5 $\alpha_{2} \beta_{2}$ acyl-CoA dehydrogenase initiates $\beta$-oxidation of 3-oxo-cholest-4-en26-oyl CoA. ACS Infect. Dis. 2016, 1, 110-125. [CrossRef] [PubMed]

87. Stirling, A.J.; Gilbert, S.E.; Conner, M.; Mallette, E.; Kimber, M.S.; Seah, S.Y.K. A key glycine in bacterial steroid-degrading acyl-CoA dehydrogenases allows flavin-ring repositioning and modulates substrate side chain specificity. Biochemistry 2020, 197, 1360-1367. [CrossRef] [PubMed]

88. Ruprecht, A.; Maddox, J.; Stirling, A.J.; Visaggio, N.; Seah, S.Y.K. Characterization of novel acyl coenzyme A dehydrogenases involved in bacterial steroid degradation. J. Bacteriol. 2015, 197, 1360-1367. [CrossRef]

89. Pidugu, L.S.; Maity, K.; Ramaswamy, K. Analysis of proteins with the "Hot dog" fold: Prediction of function and identification of catalytic residues of hypothetical proteins. BMC Struct. Biol. 2009, 9, 37. [CrossRef]

90. Haußmann, U.; Wolters, D.A.; Fränzel, B.; Eltis, L.D.; Poetsch, A. Physiological adaptation of the Rhodococcus jostii RHA1 membrane proteome to steroids as growth substrates. J. Proteome Res. 2013, 12, 1188-1198. [CrossRef]

91. Haapalainen, A.M.; Meriläinen, G.; Wierenga, R.K. The thiolase superfamily: Condensing enzymes with diverse reaction specificities. Trends Biochem. Sci. 2006, 31, 64-71. [CrossRef]

92. Schaefer, C.M.; Lu, R.; Nesbitt, N.M.; Schiebel, J.; Sampson, N.S.; Kisker, C. FadA5 a thiolase from Mycobacterium tuberculosis: A steroid-binding pocket reveals the potential for drug development against tuberculosis. Structure 2015, 23, 21-33. [CrossRef]

93. Lu, R.; Schaefer, C.M.; Nesbitt, N.M.; Kuper, J.; Kisker, C.; Sampson, N.S. Catabolism of the cholesterol side chain in Mycobacterium tuberculosis is controlled by a redox-sensitive thiol switch. ACS Infect. Dis. 2017, 3, 666-675. [CrossRef] [PubMed]

94. Casabon, I.; Swain, K.; Crowe, A.M.; Eltis, L.D.; Mohn, W.W. Actinobacterial acyl coenzyme A synthetases involved in steroid side-chain catabolism. J. Bacteriol. 2014, 196, 579-587. [CrossRef] [PubMed]

95. Gilbert, S.; Hood, L.; Seah, S.Y.K. Characterization of an aldolase involved in cholesterol side chain degradation in Mycobacterium tuberculosis. J. Bacteriol. 2018, 200, e00512-17. [CrossRef] [PubMed]

96. Thomas, S.T.; Sampson, N.S. Mycobacterium tuberculosis utilizes a unique heterotetrameric structure for dehydrogenation of the cholesterol side chain. Biochemistry 2013, 52, 2895-2904. [CrossRef]

97. Szentirmai, A. Microbial physiology of sidechain degradation of sterols. J. Ind. Microbiol. 1990, 6, 101-115. [CrossRef]

98. Aggett, R.; Mallette, E.; Gilbert, S.E.; Vachon, M.A.; Schroeter, K.L.; Kimber, M.S.; Seah, S.Y.K. The steroid side-chain-cleaving aldolase Ltp2-ChsH2DUF35 is a thiolase superfamily member with a radically repurposed active site. J. Biol. Chem. 2019, 294, 11934-11943. [CrossRef] [PubMed]

99. Yang, M.; Guja, K.E.; Thomas, S.T.; Garcia-Diaz, M.; Sampson, N.S. A distinct MaoC-like enoyl-CoA hydratase architecture mediates cholesterol catabolism in Mycobacterium tuberculosis. ACS Chem. Biol. 2014, 9, 2632-2645. [CrossRef]

100. Yuan, T.; Yang, M.; Gehring, K.; Sampson, N.S. Mycobacterium tuberculosis exploits a heterohexameric enoyl-CoA hydratase retro-aldolase complex for cholesterol catabolism. Biochemistry 2019, 58, 4224-4235. [CrossRef] 
101. Park, R.J.; Dunn, N.W.; Ide, J.A.; Park, J.; Dunn, N.W.; Ideb, J.A.; Park, R.J.; Dunn, N.W.; Ide, J.A. A catecholic 9,10-seco steroid as a product of aerobic catabolism of cholic acid by a Pseudomonas sp. Steroids 1986, 48, 439-450. [CrossRef]

102. Van Der Geize, R.; Hessels, G.I.; Van Gerwen, R.; Van Der Meijden, P.; Dijkhuizen, L. Molecular and functional characterization of $k s h A$ and $k s h B$, encoding two components of 3-ketosteroid $9 \alpha$-hydroxylase, a class IA monooxygenase, in Rhodococcus erythropolis strain SQ1. Mol. Microbiol. 2002, 45, 1007-1018. [CrossRef]

103. Petrusma, M.; Dijkhuizen, L.; Van Der Geize, R. Rhodococcus rhodochrous DSM 43269 3-ketosteroid 9 $\alpha$-hydroxylase, a twocomponent iron-sulfur-containing monooxygenase with subtle steroid substrate specificity. Appl. Environ. Microbiol. 2009, 75, 5300-5307. [CrossRef] [PubMed]

104. Petrusma, M.; Hessels, G.; Dijkhuizen, L.; van der Geize, R. Multiplicity of 3-ketosteroid-9 $\alpha$-hydroxylase enzymes in Rhodococcus rhodochrous DSM43269 for specific degradation of different classes of steroids. J. Bacteriol. 2011, 193, 3931-3940. [CrossRef] [PubMed]

105. Penfield, J.S.; Worrall, L.J.; Strynadka, N.C.; Eltis, L.D. Substrate specificities and conformational flexibility of 3-ketosteroid $9 \alpha$-hydroxylases. J. Biol. Chem. 2014, 289, 25523-25536. [CrossRef] [PubMed]

106. Ibero, J.; Galán, B.; Díaz, E.; García, J.L. Testosterone degradative pathway of Novosphingobium tardaugens. Genes $2019,10,871$. [CrossRef] [PubMed]

107. Dagley, S. Catabolism of aromatic compounds by micro-organisms. Adv. Microbial. Physiol. 1971, 6, 1-46.

108. Horinouchi, M.; Hayashi, T.; Kudo, T. The genes encoding the hydroxylase of 3-hydroxy-9,10-secoandrosta-1,3,5(10) -triene9,17-dione in steroid degradation in Comamonas testosteroni TA441. J. Steroid Biochem. Mol. Biol. 2004, 92, 143-154. [CrossRef] [PubMed]

109. Horinouchi, M.; Yamamoto, T.; Taguchi, K.; Arai, H.; Kudo, T. Meta-cleavage enzyme gene tesB is necessary for testosterone degradation in Comamonas testosteroni TA441. Microbiology 2001, 147, 3367-3375. [CrossRef]

110. Yam, K.C.; D'Angelo, I.; Kalscheuer, R.; Zhu, H.; Wang, J.X.; Snieckus, V.; Ly, L.H.; Converse, P.J.; Jacobs, W.R.; Strynadka, N.; et al. Studies of a ring-cleaving dioxygenase illuminate the role of cholesterol metabolism in the pathogenesis of Mycobacterium tuberculosis. PLoS Pathog. 2009, 5, e1000344. [CrossRef]

111. Van der Geize, R.; Yam, K.; Heuser, T.; Wilbrink, M.H.; Hara, H.; Anderton, M.C.; Sim, E.; Dijkhuizen, L.; Davies, J.E.; Mohn, W.W.; et al. A gene cluster encoding cholesterol catabolism in a soil Actinomycete provides insight into Mycobacterium tuberculosis survival in macrophages. Proc. Natl. Acad. Sci. USA 2007, 104, 1947-1952. [CrossRef] [PubMed]

112. Horinouchi, M.; Hayashi, T.; Koshino, H.; Yamamoto, T.; Kudo, T. Gene encoding the hydrolase for the product of the metacleavage reaction in testosterone degradation by Comamonas testosteroni. Appl. Environ. Microbiol. 2003, 69, 2139-2152. [CrossRef]

113. Seah, S.Y.K.; Ke, J.; Denis, G.; Horsman, G.P.; Fortin, P.D.; Whiting, C.J.; Eltis, L.D. Characterization of a C-C bond hydrolase from Sphingomonas wittichii RW1 with novel specificities towards polychlorinated biphenyl metabolites. J. Bacteriol. 2007, 189, 4038-4045. [CrossRef]

114. Lack, N.; Lowe, E.D.; Liu, J.; Eltis, L.D.; Noble, M.E.M.; Sim, E.; Westwood, I.M. Structure of HsaD, a steroid-degrading hydrolase, from Mycobacterium tuberculosis. Acta Crystallogr. Sect. F Struct. Biol. Cryst. Commun. 2007, 64, 2-7. [CrossRef]

115. Lack, N.A.; Yam, K.C.; Lowe, E.E.; Horsman, G.P.; Owen, R.L.; Sim, E.; Eltis, L.D. Characterization of a carbon-carbon hydrolase from Mycobacterium tuberculosis involved in cholesterol metabolism. J. Biol. Chem. 2010, 285, 434-443. [CrossRef] [PubMed]

116. Horinouchi, M.; Hayashi, T.; Koshino, H.; Kurita, T.; Kudo, T. Identification of 9,17-dioxo-1,2,3,4,10,19-hexanorandrostan-5oic acid, 4-hydroxy-2-oxohexanoic acid, and 2-hydroxyhexa-2,4-dienoic acid and related enzymes involved in testosterone degradation in Comamonas testosteroni TA441. Appl. Environ. Microbiol. 2005, 71, 5275-5281. [CrossRef] [PubMed]

117. Carere, J.; McKenna, S.E.; Kimber, M.S.; Seah, S.Y.K. Characterization of an aldolase-dehydrogenase complex from the cholesterol degradation pathway of Mycobacterium tuberculosis. Biochemistry 2013, 52, 3502-3511. [CrossRef]

118. Fahrbach, M.; Krauss, M.; Preiss, A.; Kohler, H.P.E.; Hollender, J. Anaerobic testosterone degradation in Steroidobacter denitrificansidentification of transformation products. Environ. Pollut. 2010, 158, 2572-2581. [CrossRef] [PubMed]

119. Fahrbach, M.; Kuever, J.; Remesch, M.; Huber, B.E.; Kämpfer, P.; Dott, W.; Hollender, J. Steroidobacter denitrificans gen. nov., sp. nov., a steroidal hormone-degrading $\gamma$-Proteobacterium. Int. J. Syst. Evol. Microbiol. 2008, 58, 2215-2223. [CrossRef] [PubMed]

120. Tarlera, S.; Denner, E.B.M. Sterolibacterium denitrificans gen. nov., sp. nov., a novel cholesterol-oxidizing, denitrifying member of the $\beta$-Proteobacteria. Int. J. Syst. Evol. Microbiol. 2003, 53, 1085-1091. [CrossRef] [PubMed]

121. Shih, C.-J.; Chen, Y.-L.; Wang, C.-H.; Wei, S.T.-S.; Lin, I.-T.; Ismail, W.A.; Chiang, Y.-R. Biochemical mechanisms and microorganisms involved in anaerobic testosterone metabolism in estuarine sediments. Front. Microbiol. 2017, 8, 1520. [CrossRef] [PubMed]

122. Wang, P.H.; Yu, C.P.; Lee, T.H.; Lin, C.W.; Ismail, W.; Wey, S.P.; Kuo, A.T.; Chiang, Y.R. Anoxic androgen degradation by the denitrifying bacterium Sterolibacterium denitrificans via the 2,3-seco pathway. Appl. Environ. Microbiol. 2014, 80, $3442-3452$. [CrossRef]

123. Wang, P.-H.; Leu, Y.-L.; Ismail, W.; Tang, S.-L.; Tsai, C.-Y.; Chen, H.-J.; Kao, A.-T.; Chiang, Y.-R. Anaerobic and aerobic cleavage of the steroid core ring structure by Steroidobacter denitrificans. J. Lipid Res. 2013, 54, 1493-1504. [CrossRef] [PubMed]

124. Yang, F.-C.; Chen, Y.-L.; Tang, S.-L.; Yu, C.-P.; Wang, P.-H.; Ismail, W.; Wang, C.-H.; Ding, J.-Y.; Yang, C.-Y.C.-Y.; Yang, C.-Y.C.-Y.; et al. Integrated multi-omics analyses reveal the biochemical mechanisms and phylogenetic relevance of anaerobic androgen biodegradation in the environment. ISME J. 2016, 10, 1-17. [CrossRef] [PubMed] 
125. Crowe, A.M.; Casabon, I.I.; Brown, K.L.; Liu, J.; Lian, J.; Rogalski, J.C.; Hurst, T.E.; Snieckus, V.; Foster, L.J.; Eltis, L.D. Catabolism of the last two steroid rings in Mycobacterium tuberculosis and other bacteria. mBio 2017, 8, 1-16. [CrossRef]

126. Gadbery, J.; Round, J.; Yuan, T.; Wipperman, M.F.; Story, K.T.; Crowe, A.; Casabon, I.; Liu, J.; Yang, X.; Eltis, L.D.; et al. IpdE1-IpdE2 is a heterotetrameric acyl coenzyme A dehydrogenase that is widely distributed in steroid-degrading bacteria. Biochemistry 2020, 59, 1113-1123. [CrossRef]

127. Horinouchi, M.; Hayashi, T.; Koshino, H.; Malon, M.; Hirota, H.; Kudo, T. Identification of 9 $\alpha$-hydroxy-17-oxo-1,2,3,4,10,19hexanorandrostan- 5-oic acid in steroid degradation by Comamonas testosteroni TA441 and its conversion to the corresponding 6-en-5-oyl coenzyme A (CoA) involving open reading frame 28 (ORF28)- and ORF30-encoded acyl-CoA dehydrogenases. J. Bacteriol. 2014, 196, 3598-3608. [PubMed]

128. Horinouchi, M.; Koshino, H.; Malon, M.; Hirota, H.; Hayashi, T. Steroid degradation in Comamonas testosteroni TA441: Identification of metabolites and the genes involved in the reactions necessary before D-ring cleavage. Appl. Environ. Microbiol. 2018, 84, e01324-18. [CrossRef] [PubMed]

129. Horinouchi, M.; Malon, M.; Hirota, H.; Hayashi, T. Identification of 4-methyl-5-oxo-octane-1,8-dioic acid and the derivatives as metabolites of steroidal C,D-ring degradation in Comamonas testosteroni TA441. J. Steroid Biochem. Mol. Biol. 2019, 185, 277-286. [CrossRef] [PubMed]

130. Horinouchi, M.; Koshino, H.; Malon, M.; Hirota, H.; Hayashi, T. Identification of 9-oxo-1,2,3,4,5,6,10,19-octanor-13,17-secoandrost8(14)-ene-7,17-dioic acid as a metabolite of steroid degradation in Comamonas testosteroni TA441 and the genes involved in the conversion. J. Steroid Biochem. Mol. Biol. 2019, 185, 268-276. [CrossRef] [PubMed]

131. Helenius, A.; Simons, K. Solubilization of membranes by detergents. BBA Rev. Biomembr. 1975, 415, 29-79. [CrossRef]

132. Begley, M.; Gahan, C.G.M.; Hill, C. The interaction between bacteria and bile. FEMS Microbiol. Rev. 2005, 29, 625-651. [CrossRef]

133. Bernstein, C.; Bernstein, H.; Payne, C.M.; Beard, S.E.; Schneider, J. Bile salt activation of stress response promoters in Escherichia coli. Curr. Microbiol. 1999, 39, 68-72. [CrossRef] [PubMed]

134. Cremers, C.M.; Knoefler, D.; Vitvitsky, V.; Banerjee, R.; Jakob, U. Bile salts act as effective protein-unfolding agents and instigators of disulfide stress in vivo. Proc. Natl. Acad. Sci. USA 2014, 111, E1610-E1619. [CrossRef] [PubMed]

135. Gunn, J.S. Mechanisms of bacterial resistance and response to bile. Microbes Infect. 2000, 2, 907-913. [CrossRef]

136. Nikaido, H. Molecular basis of bacterial outer membrane permeability revisited. Microbiol. Mol. Biol. Rev. 2003, 67, 593-656. [CrossRef]

137. Hancock, R.E.W. The bacterial outer membrane as a drug barrier. Trends Microbiol. 1997, 5, 37-42. [CrossRef]

138. Paul, S.; Alegre, K.O.; Holdsworth, S.R.; Rice, M.; Brown, J.A.; Mcveigh, P.; Kelly, S.M.; Law, C.J. A single-component multidrug transporter of the major facilitator superfamily is part of a network that protects Escherichia coli from bile salt stress. Mol. Microbiol. 2014, 92, 872-884. [CrossRef] [PubMed]

139. Lee, C.Y.; Liu, W.H. Production of androsta-1,4-diene-3,17-dione from cholesterol using immobilized growing cells of Mycobacterium sp. NRRL B-3683 adsorbed on solid carriers. Appl. Microbiol. Biotechnol. 1992, 36, 598-603. [CrossRef]

140. Perez, C.; Falero, A.; Llanes, N.; Hung, B.R.; Hervé, M.E.; Palmero, A.; Martí, E. Resistance to androstanes as an approach for androstandienedione yield enhancement in industrial mycobacteria. J. Ind. Microbiol. Biotechnol. 2003, 30, 623-626. [CrossRef]

141. Göhler, A.; Xiong, G.; Paulsen, S.; Trentmann, G.; Maser, E. Testosterone-inducible regulator is a kinase that drives steroid sensing and metabolism in Comamonas testosteroni. J. Biol. Chem. 2008, 283, 17380-17390. [CrossRef]

142. Gong, W.; Xiong, G.; Maser, E. Oligomerization and negative autoregulation of the LysR-type transcriptional regulator HsdR from Comamonas testosteroni. J. Steroid Biochem. Mol. Biol. 2012, 132, 203-211. [CrossRef]

143. Kendall, S.L.; Burgess, P.; Balhana, R.; Withers, M.; Ten Bokum, A.; Lott, J.S.; Gao, C.; Uhia-Castro, I.; Stoker, N.G. Cholesterol utilization in mycobacteria is controlled by two TetR-type transcriptional regulators: $k s t R$ and kstR2. Microbiology 2010, 156, 1362-1371. [CrossRef] [PubMed]

144. García-Fernández, E.; Medrano, F.J.; Galán, B.; García, J.L. Deciphering the transcriptional regulation of cholesterol catabolic pathway in mycobacteria: Identification of the inducer of KstR repressor. J. Biol. Chem. 2014, 289, 17576-17588. [CrossRef] [PubMed]

145. Casabon, I.; Zhu, S.H.; Otani, H.; Liu, J.; Mohn, W.W.; Eltis, L.D. Regulation of the KstR2 regulon of Mycobacterium tuberculosis by a cholesterol catabolite. Mol. Microbiol. 2013, 89, 1201-1212. [CrossRef]

146. Taoka, H.; Yokoyama, Y.; Morimoto, K.; Kitamura, N.; Tanigaki, T.; Takashina, Y.; Tsubota, K.; Watanabe, M. Role of bile acids in the regulation of the metabolic pathways. World J. Diabetes July World J. Diabetes 2016, 10, 260-270. [CrossRef]

147. Chiang, J.Y.L. Bile acid metabolism and signaling. Compr. Physiol. 2013, 3, 1191-1212.

148. Li, W. Bile acid secreted by male sea lamprey that acts as a sex pheromone. Science 2002, 296, 138-141. [CrossRef]

149. Li, K.; Scott, A.M.; Brant, C.O.; Fissette, S.D.; Riedy, J.J.; Hoye, T.R.; Li, W. Bile salt-like dienones having a novel skeleton or a rare substitution pattern function as chemical cues in adult sea lamprey. Org. Lett. 2017, 19, 4444-4447. [CrossRef] [PubMed]

150. Brant, C.O.; Chung-Davidson, Y.-W.; Li, K.; Scott, A.M.; Li, W. Biosynthesis and release of pheromonal bile salts in mature male sea lamprey. BMC Biochem. 2013, 14, 30. [CrossRef]

151. Zhang, Z.; Zhang, Q.; Dexheimer, T.S.; Ren, J.; Neubig, R.R.; Li, W. Two highly related odorant receptors specifically detect a-bile acid pheromones in sea lamprey (Petromyzon marinus). J. Biol. Chem. 2020, 295, 12153-12166. [CrossRef] [PubMed]

152. Hahn, M.A.; Effertz, C.; Bigler, L.; von Elert, E. $5 \alpha$-cyprinol sulfate, a bile salt from fish, induces diel vertical migration in Daphnia. Elife 2019, 8, e44791. [CrossRef] 
153. Doyle, W.I.; Dinser, J.A.; Cansler, H.L.; Zhang, X.; Dinh, D.D.; Browder, N.S.; Riddington, I.M.; Meeks, J.P. Faecal bile acids are natural ligands of the mouse accessory olfactory system. Nat. Commun. 2016, 7, 11936. [CrossRef] [PubMed]

154. Li, K.; Brant, C.O.; Siefkes, M.J.; Kruckman, H.G.; Li, W. Characterization of a novel bile alcohol sulfate released by sexually mature male sea lamprey (Petromyzon marinus). PLoS ONE 2013, 8, e68157. [CrossRef] [PubMed]

155. Schulenburg, H.; Félix, M.A. The natural biotic environment of Caenorhabditis elegans. Genetics 2017, 206, 55-86. [CrossRef] [PubMed]

156. Frézal, L.; Félix, M.A. C. elegans outside the Petri dish. Elife 2015, 30, 4. [CrossRef] [PubMed]

157. Maglich, J.M.; Sluder, A.; Guan, X.; Shi, Y.; McKee, D.D.; Carrick, K.; Kamdar, K.; Willson, T.M.; Moore, J.T. Comparison of complete nuclear receptor sets from the human, Caenorhabditis elegans and Drosophila genomes. Genome Biol. 2001, 2, RESEARCH0029. [CrossRef]

158. Motola, D.L.; Cummins, C.L.; Rottiers, V.; Sharma, K.K.; Li, T.; Li, Y.; Suino-Powell, K.; Xu, H.E.; Auchus, R.J.; Antebi, A.; et al. Identification of ligands for DAF-12 that govern dauer formation and reproduction in C. elegans. Cell 2006, 124, 1209-1223. [CrossRef]

159. Aguilaniu, H.; Fabrizio, P.; Witting, M. The role of dafachronic acid signaling in development and longevity in Caenorhabditis elegans: Digging deeper using cutting-edge analytical chemistry. Front. Endocrinol. Lausanne 2016, 7, 1-10. [CrossRef]

160. Mansell, D.S.; Bryson, R.J.; Harter, T.; Webster, J.P.; Kolodziej, E.P.; Sedlak, D.L. Fate of endogenous steroid hormones in steer feedlots under simulated rainfall-induced runoff. Environ. Sci. Technol 2011, 45, 8811-8818. [CrossRef]

161. Gravert, T.K.O.; Fauser, P.; Olsen, P.; Hansen, M. In situ formation of environmental endocrine disruptors from phytosterol degradation: A temporal model for agricultural soils. Environ. Sci. Process. Impacts 2021, 23, 855-866. [CrossRef]

162. Matsumoto, A.M.; Marck, B.T. DEA Agreement No. DEA-04- P0007 Final Report [Analysis of the Androgenic and Anabolic Activities of 1,4-Androstadien-3,17-dione and 19-nor-4,9(10)- Androstadienedione in Male Sprague Dawley Rats]. DEA Document ID DEA-2008-0007-0003. 2006. Available online: https://www.regulations.gov/document/DEA-2008-0007-0003 (accessed on 18 August 2017).

163. Bhasin, S.; Jasuja, R. Pharmacological Analysis of Boldione and 19-nor-4,9(10)-Androstadienedione for Androgenic Activity Using C3H10T1/2 Stem Cells. DEA Document ID DEA-2008-0007-0002. 2005. Available online: https://www.regulations.gov/ document/DEA-2008-0007-0002 (accessed on 18 August 2017).

164. Barceloux, D.G.; Palmer, R.B. Anabolic-Androgenic steroids. Disease-a-Month 2013, 59, 226-248. [CrossRef]

165. Kicman, A. Pharmacology of anabolic steroids. Br. J. Pharmacol. 2008, 154, 502-521. [CrossRef]

166. Hou, L.; Xie, Y.; Ying, G.; Fang, Z. Developmental and reproductive characteristics of western mosquitofish (Gambusia affinis) exposed to paper mill effluent in the Dengcun River, Sihui, South China. Aquat. Toxicol. 2011, 103, 140-149. [CrossRef] [PubMed]

167. Brockmeier, E.K.; Jayasinghe, B.S.; Pine, W.E.; Wilkinson, K.A.; Denslow, N.D. Exposure to paper mill effluent at a site in north central Florida elicits molecular-level changes in gene expression indicative of progesterone and androgen exposure. PLoS ONE 2014, 9, e106644. [CrossRef] [PubMed]

168. Parks, L.G.; Lambright, C.S.; Orlando, E.F.; Guillette, L.J.; Ankley, G.T.; Gray, L.E. Masculinization of female mosquitofish in kraft mill effluent-contaminated fenholloway river water is associated with androgen receptor agonist activity. Toxicol. Sci. 2001, 62, 257-267. [CrossRef] [PubMed]

169. Carson, J.; Jenkins, R.; Wilson, E.; Howell, W.; Moore, R. Naturally occurring progesterone in Loblolly pine: A major steroid precursor of environmental androgens. Environ. Toxicol. Chem. 2007, 27, 1273-1278. [CrossRef]

170. Dlugovitzky, D.G.; Fontela, M.S.; Martinel Lamas, D.J.; Valdez, R.A.; Romano, M.C. Mycobacterium smegmatis synthesizes in vitro androgens and estrogens from different steroid precursors. Can. J. Microbiol. 2015, 61, 451-455. [CrossRef] [PubMed]

171. Jenkins, R.L.; Wilson, E.M.; Angus, R.A.; Howell, W.M.; Kirk, M.; Moore, R.; Nance, M.; Brown, A. Production of androgens by microbial transformation of progesterone in vitro: A model for androgen production in rivers receiving paper mill effluent. Environ. Health Perspect. 2004, 112, 1508-1511. [CrossRef]

172. Enmark, E.; Gustafsson, J.Å. Nematode genome sequence dramatically extends the nuclear receptor superfamily. Trends Pharmacol. Sci. 2000, 21, 85-87. [CrossRef]

173. Sluder, A.E.; Mathews, S.W.; Hough, D.; Yin, V.P.; Maina, C.V. The nuclear receptor superfamily has undergone extensive proliferation and diversification in nematodes. Genome Res. 1999, 9, 103-120.

174. Taubert, S.; Ward, J.D.; Yamamoto, K.R. Nuclear hormone receptors in nematodes: Evolution and function. Mol. Cell. Endocrinol. 2011, 334, 49-55. [CrossRef]

175. Donova, M.V.; Egorova, O.V. Microbial steroid transformations: Current state and prospects. Appl. Microbiol. Biotechnol. 2012, 94, 1423-1447. [CrossRef] [PubMed]

176. Bortolini, O.; Medici, A.; Poli, S. Biotransformations on steroid nucleus of bile acids. Steroids 1997, 62, 564-577. [CrossRef]

177. Bouchier, I.A.D. The medical treatment of gallstones. Ann. Rev. Med. 1980, 31, 59-77. [CrossRef] [PubMed]

178. Beuers, U.; Spengler, U.; Kruis, W.; Aydemir, Ü.; Wiebecke, B.; Heldwein, W.; Weinzierl, M.; Pape, G.R.; Sauerbruch, T.; Paumgartner, G. Ursodeoxycholic acid for treatment of primary sclerosing cholangitis: A placebo-controlled trial. Hepatology 1992, 16, 707-714. [CrossRef] [PubMed]

179. Kim, E.; Cho, J.H.; Kim, E.; Kim, Y.J. Ursodeoxycholic acid inhibits the proliferation of colon cancer cells by regulating oxidative stress and cancer stem-like cell growth. PLOS ONE 2017, 12, 1-11. [CrossRef] [PubMed] 
180. Braun, M.; Sun, B.; Anselment, B.; Weuster-Botz, D. Novel whole-cell biocatalysts with recombinant hydroxysteroid dehydrogenases for the asymmetric reduction of dehydrocholic acid. Appl. Microbiol. Biotechnol. 2012, 95, 1457-1468. [CrossRef]

181. Bordoni, A.; Amaretti, A.; Leonardi, A.; Boschetti, E.; Danesi, F.; Matteuzzi, D.; Roncaglia, L.; Raimondi, S.; Rossi, M. Cholesterollowering probiotics: In vitro selection and in vivo testing of bifidobacteria. Appl. Microbiol. Biotechnol. 2013, 97, 8273-8281. [CrossRef]

182. Ooi, L.G.; Liong, M.T. Cholesterol-lowering effects of probiotics and prebiotics: A review of in vivo and in vitro findings. Int. J. Mol. Sci. 2010, 11, 2499-2522. [CrossRef]

183. Kumar, R.; Grover, S.; Batish, V.K. Hypocholesterolaemic effect of dietary inclusion of two putative probiotic bile salt hydrolaseproducing Lactobacillus plantarum strains in Sprague-Dawley rats. Br. J. Nutr. 2011, 105, 561-573. [CrossRef] 